
Donantes

El Centro Internacional de Investigación Forestal (CIFOR) se financia con los aportes de gobiernos, organizaciones internacionales de desarrollo, fundaciones privadas y organizaciones regionales. En el 2004, CIFOR recibió apoyo económico de la Agencia Alemana de Cooperación Técnica (GTZ), Australia, Banco Asiático de Desarrollo (ADB), Banco Mundial, Bélgica, Brasil, Canadá, Carrefour, Centro Internacional de Investigación y Desarrollo (IDRC), China, CIRAD, Comisión Europea, Corea, Estados Unidos, Filipinas, Finlandia, Fondo Internacional de Desarrollo Agrícola (IFAD), Francia, Fundación Africana para la Vida Silvestre (AWF), Fundación Conservación Internacional (CIF), Fundación de Bosques Tropicales, Fundación Ford, Fundación Overbrook, Fundación para la Naturaleza (WWF), Holanda, Indonesia, Instituto de Desarrollo de Ultramar (ODI), Instituto de los Recursos del Mundo (WRI), Instituto Peruano de Recursos Naturales Renovables (INRENA), Italia, Japón, Manejo de Recursos Innovadores (IRM), Ministerio de Cooperación Económica y Desarrollo del Gobierno Alemán (BMZ), Noruega, Organización Africana de Bosques $(\mathrm{OAB})$, Organización de las Naciones Unidas para la Agricultura y Alimentación (FAO), Organización Internacional de Maderas Tropicales (ITTO), Programa Ambiental de las Naciones Unidas (UNEP), Reino Unido, Suecia, Suiza, The Nature Conservancy (TNC), Universidad Sueca de Ciencias Agrícolas (SLU) y Universidad Waseda.

Traducción del texto original en inglés: "Payments for environmental services: Some nuts and bolts", CIFOR 2005

\section{ISSN 0854-9818}

๑ 2006 del Centro Internacional de Investigación Forestal Todos los derechos reservados.

Fotos de portada: Sven Wunder

Centro Internacional de Investigación Forestal Dirección postal: P.O. Box 6596 JKPWB, Jakarta 10065, Indonesia Oficinas: Jl. CIFOR, Situ Gede, Sindang Barang, Bogor Barat 16680, Indonesia Tel.: +62 (251) 622622; Fax: +62 (251) 622100

E-mail: cifor@cgiar.org

Web site: http://www.cifor.cgiar.org 
Pagos por servicios ambientales:

Principios básicos esenciales

Sven Wunder 


\section{Índice}

Acronismos y abreviaturas iii

Agradecimientos iii

Resumen 1

1. Introducción 1

2. Definición, términos y rasgos claves 3

2.1 Definición 3

2.2 Terminología 4

2.3 Rasgos claves 4

2.4 Tipos de PSA 7

3. ¿Cómo evaluar la eficiencia del PSA? 8

4. ¿Para qué escenarios de uso de la tierra se emplea el PSA? 9

5. ¿Eficiencia o equidad? 11

6. ¿A quién pagar? 12

7. ¿Cómo pagar? 14

8. ¿EI PSA a favor de los pobres? 16

8.1 Acceso a la participación en el PSA 16

8.2 Efecto en los vendedores de SA 18

8.3 Efecto en los pobres que no venden SA 19

9. Conclusión y perspectivas 20

9.1 ¿Cuándo es el PSA el mejor instrumento para la conservación? 20

9.2 ¿Cómo diseñar un esquema de PSA? 21

$\begin{array}{ll}\text { Literatura } & 23\end{array}$ 


\section{Acronismos y abreviaturas}

\begin{tabular}{|c|c|}
\hline CIFOR & Centro Internacional de Investigación Forestal (Indonesia) \\
\hline COSUDE & Agencia Suiza para el Desarrollo y la Cooperación \\
\hline IPCC & Panel de las Naciones Unidas para el Cambio Climático \\
\hline IVA & Impuesto al valor agregado \\
\hline MDL & Mecanismo de Desarrollo Limpio (según el Protocolo de Kyoto) \\
\hline MFS & Manejo forestal sustentable \\
\hline ONG & Organización no gubernamental \\
\hline PICD & Proyecto integrado de conservación y desarrollo \\
\hline PFNM & Producto forestal no maderable \\
\hline PROFAFOR & $\begin{array}{l}\text { Programa FACE de Forestación para el Ecuador (FACE - Programa de forestación para } \\
\text { la absorción de emisiones de dióxido de carbono en Ecuador) }\end{array}$ \\
\hline PSA & Pago por servicios ambientales \\
\hline RISEMP & $\begin{array}{l}\text { Proyecto Regional de Manejo Integrado de Ecosistemas Silvopastoriles (Colombia, } \\
\text { Costa Rica y Nicaragua) }\end{array}$ \\
\hline RUPES & $\begin{array}{l}\text { Gratificación a familias pobres del las zonas altas por servicios ambientales (programa } \\
\text { para promocionar PSA en Asia) }\end{array}$ \\
\hline SA & Servicio ambiental \\
\hline
\end{tabular}

\section{Agradecimientos}

Se agradece a Lykke Andersen y Ricardo Godoy por la revisión externa del documento. A Kathryn Anderson, Brian Belcher, Bruce Campbell, David Kaimowitz y Douglas Sheil por sus valiosos comentarios. La versión final de este trabajo se benefició de las discusiones con mis colegas durante el trabajo de campo; en especial, Nina Robertson (Bolivia), Montserrat Albán (Ecuador), Tobias Wünscher (Costa Rica), Bui Dung The y Enrique Ibarra (Vietnam) y otros colegas del CIFOR que trabajan en la iniciativa de concesiones comunitarias para la conservación en Setulang (Indonesia). A la Agencia Suiza para el Desarrollo y la Cooperación (COSUDE) por el apoyo financiero parcial al trabajo de campo en el que se sustenta este estudio. 


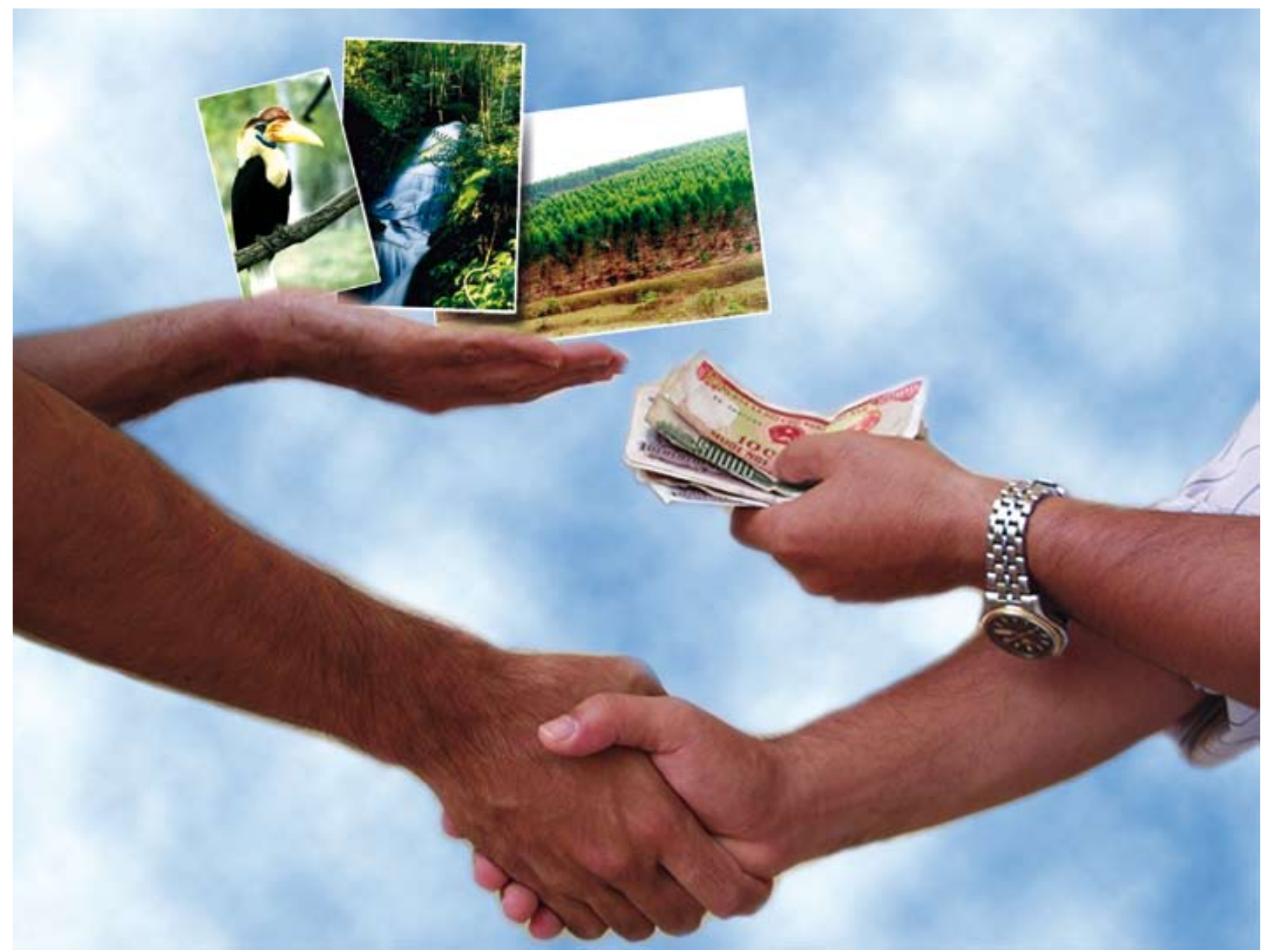

El principio de condicionamiento - sólo se paga si el servicio es realmente ofrecidoes el rasgo más innovador del PSA, que lo diferencia de las herramientas tradicionales de conservación (Fotos: Brian Belcher, Christian Cossalter y Sven Wunder). 


\section{Resumen}

Los pagos por servicios ambientales (PSA) son parte de un paradigma de conservación nuevo y más directo, que explícitamente reconoce la necesidad de crear puentes entre los intereses de los propietarios de la tierra y los usuarios de los servicios. Valoraciones teóricas elocuentes han demostrado las ventajas absolutas del PSA sobre los enfoques tradicionales de conservación. En los trópicos existen algunas experiencias piloto en PSA; sin embargo, todavía hay mucho escepticismo entre quienes trabajan en el campo y entre los posibles compradores de los servicios. Este trabajo pretende ayudar a desmitificar el PSA para el neófito, empezando con una definición simple y coherente del término. A continuación se ofrecen sugerencias prácticas para el diseño de PSA y se sopesa el nicho probable para el PSA en el portafolio de enfoques de conservación. Esta evaluación se basa en una revisión de literatura y observaciones de campo en investigaciones en América Latina y Asia. Se concluye que la voluntad de pago de los usuarios aumentará únicamente si se logra demostrar que se han logrado ganancias positivas ('adicionalidad') a partir de una línea base cuidadosamente establecida, si se desarrollan procesos para fomentar la confianza en quienes proveen los servicios, y si se entiende mejor la dinámica de formas de subsistencia de quienes reciben el PSA. EI PSA se adapta mejor a escenarios de amenaza intermedia y/o proyectada; más que todo, terrenos marginales con moderados costos de oportunidad para la conservación. Quienes enfrentan niveles medios de degradación ambiental tiene mayores probabilidades de recibir el PSA que quienes viven en relativa armonía con la naturaleza. La forma de pago del PSA (en efectivo o en especie) depende más que todo del contexto. Los pobres podrían beneficiarse con el PSA, aunque su acceso pudiera verse limitado y restringido por la posesión de la tierra: los pobres sin tierra estarían fuera del esquema. El PSA es un enfoque de conservación muy promisorio que puede beneficiar a compradores y vendedores y mejorar la base de recursos, pero es poco probable que supere a que otros instrumentos de conservación.

Palabras claves: servicios ambientales, medios de vida rural, conservación, incentivos económicos, administración de recursos naturales, proyectos integrados de conservación y desarrollo, Bolivia, Brasil, Indonesia.

\section{Introducción}

Después del Informe Brundtland (1987) y de la conferencia de Río 1992, la conservación de los trópicos tomó un rumbo más orientado hacia el bienestar de la gente. Esta tendencia reflejaba el saber popular de que aliviar la pobreza es la única forma de conservar y proteger el ambiente. Los proyectos integrados de conservación y desarrollo (PICD) y el manejo forestal sostenible eran los dos instrumentos principales para, simultáneamente, mejorar los ingresos y conservar el ambiente (Salafsky y Wollenberg 2000, Pearce et al. 2003). Sin embargo, a pesar de algunos éxitos dispersos, ninguno de los dos enfoques ha logrado hasta ahora cambios significativos en el uso de la tierra en los trópicos (Brandon et al. 1998, Sayer 1995) ni en las prácticas silviculturales (Poore 2003, Rice 1997). Además, hay serias dudas en cuanto a su capacidad para empatar las agendas de conservación y alivio de la pobreza, cuando las contradicciones y trade-offs superan a las sinergias (Adams et al. 2004, Wunder 2001).

A partir de estas ideas, se han dado serios debates sobre la necesidad de contar con nuevos paradigmas para la conservación. El concepto de pago por servicios ambientales (PSA) está entre los enfoques que promueven más directamente la conservación (Hardner y Rice 2002, Niesten y Rice 2004, Scherr et al. 2004, Ferraro y Kiss 2002). A medida que los hábitats naturales y silvestres van disminuyendo, los servicios ambientales (SA) antes ofrecidos de manera gratuita por la Madre Naturaleza se ven cada vez más amenazados. Esta creciente escasez los vuelve sujetos potenciales de comercialización. La idea central del PSA es que los beneficiarios externos de los SA paguen - de manera directa, contractual y condicionadaa los propietarios y usuarios locales por adoptar prácticas que aseguren la conservación y restauración de ecosistemas.

Estemétodocontingentedifierefundamentalmente de otros enfoques de conservación. En vez de presuponer soluciones 'gana-gana' (win-win, en inglés), este enfoque explícitamente reconoce duros conflictos en paisajes con fuertes $y$ crecientes presiones por el uso de la tierra, y busca conciliar intereses opuestos mediante la compensación. Se ha dicho, de manera convincente, que los esquemas de PSA son más efectivos en términos de costos que los PICD (Ferraro y Simpson 2002, Simpson y Sedjo 1996). Si bien en varias economías desarrolladas existen esquemas de PSA, en los países en desarrollo han sido poco probados. Hay muchas iniciativas incipientes (Landell-Mills y Porras 2002, Pagiola et al. 2002), pero pocas experiencias reales en las que el dinero realmente cambie de manos de manera condicionada, p.e. en Costa Rica y una 
docena de otras iniciativas, sobre todo en países latinoamericanos.

Actualmente, se destacan cuatro tipos de SA:

1. Secuestro y almacenamiento de carbono: por ejemplo, una empresa eléctrica del hemisferio norte paga a campesinos del trópico por plantar y mantener árboles.

2. Protección de la biodiversidad: por ejemplo, donantes que pagan a los pobladores locales por proteger y restaurar áreas para crear un corredor biológico.

3. Protección de cuencas hidrográficas: por ejemplo, los usuarios aguas abajo pagan a los dueños de fincas aguas arriba por adoptar usos de la tierra que limiten la deforestación, la erosión del suelo, riesgos de inundación, etc.

4. Belleza escénica: por ejemplo, una empresa de turismo paga a una comunidad local por no cazar en un bosque usado para turismo de observación de la vida silvestre.

A menudo se pueden ofrecer varios servicios de manera sinérgica $y$, entonces, se pueden organizar paquetes de pago entre varios usuarios. Pero no todos los servicios están realmente amenazados ni son escasos, ni todos los usuarios están dispuestos a pagar. Además, otros servicios pudieran recibir pagos parciales; por ejemplo, una plantación de crecimiento rápido maximiza el secuestro de carbono, pero no es particularmente rica en diversidad, ni mejora la provisión de agua ni es atractiva para el turista. Se pudieran comercializar otros servicios ambientales (p.e. áreas silvestres que ofrecen servicios de polinización a la agricultura), pero hasta ahora sólo los cuatro servicios mencionados tienen un valor comercial significativo.

¿Cómo han recibido este paradigma los círculos de conservación y de desarrollo rural? Es justo decir que las reacciones han sido diversas. Quienes abogan por el PSA advierten que se requieren innovacionesurgentes, ya que los enfoques actuales logran pocos resultados mintras que los fondos de financiamiento son cada vez menores, que el PSA puede conseguir nuevos recursos financieros (especialmente del sector privado) y mejorar las condiciones de vida de las comunidades pobres que venden servicios. Los escépticos, sin embargo, temen que el PSA "levantará cercas de nuevo" al separar la conservación y el desarrollo; que una distribución asimétrica del poder significa que poderosos consorcios conservacionistas arrebaten a las comunidades sus legítimas aspiraciones al desarrollo, y que la conservación comercial pudiera erosionar valores de conservación arraigados culturalmente y sin fines comerciales (Romero y Andrade 2004, Karsenty y Nasi 2004, Karsenty 2004, Vogel 2002). Por otra parte, entre quienes se oponen al PSA, algunos también tienen intereses creados. Para un donante, el dinero que pasa de un comprador a un vendedor de servicios obviamente tiene menos impacto mediático que un proyecto de desarrollo rural multifacético -y por lo tanto, es más difícil de vender a la opinión pública que quiere creer en intervenciones puntuales que cambien el sistema para el bien común, y no en externalidades infinitas que requieren de pagos infinitos. ONG y consultores sobre desarrollo integral arriesgan perder su razón de ser si el PSA remplazara a los PICD, ya que se necesitaría un nuevo set de habilidades totalmente diferentes, como monitoreo de los servicios y usos de la tierra, facilitación de negociaciones e intermediación financiera. Para los reguladores del uso de la tierra, el PSA implica que se reconozca el derecho de quien recibe el pago a determinar libremente el uso de su tierra, inclusive cuando haya conflictos con regulaciones de uso ya existentes. No es de sorprenderse, entonces, que muchos ven al PSA como una amenaza y no como una oportunidad, a pesar de sus virtudes potenciales.

En esta etapa embrionaria, la adopción del PSA en los trópicos enfrenta dos obstáculos y una barrera de comunicación. El primer obstáculo es la demanda limitada: muy pocos usuarios de los servicios tienen confianza en el mecanismo como para pagar -en unos casos porque el nexo entre el uso de la tierra y la provisión del SA es ambiguo o poco evidente (ver análisis más adelante). El segundo obstáculo es el poco conocimiento sobre la dinámica de abastecimiento de SA. Donde hay demanda y voluntad de pago, ¿cuáles son las precondiciones institucionales que los oferentes del servicio exigen para negociar un PSA? Si se inicia un sistema de PSA, ¿cómo funcionará la transferencia de beneficios contingentes y directos hacia comunidades pobres y remotas -tanto como incentivo por la salvaguarda de recursos como en las condiciones de vida locales? Se sabe muy poco y se necesitan más experimentos puntuales. Finalmente, la comunicación del concepto de PSA es un problema. Quienes lo proponen por lo común usan una racionalidad económica, y quienes lo adversan se basan en otras ciencias sociales (antropología, sociología, psicología, ciencias políticas). Obviamente, es necesario establecer mediaciones entre ambos puntos.

Este trabajo no analiza el primer obstáculo -falta de voluntad de pago- ya que ha sido ampliamente analizado por otros autores (Balmford et al. 2002, Balmford y Whitten 2003, James et al. 2001, Wunder et al. 2004, Gutman 2003). Nuestro interés es el segundo obstáculo: los mecanismos de incentivos y medios de vida, que comparativamente han recibido menos atención. Esperamos que este trabajo también ayude a clarificar el concepto de PSA entre los actores relacionados con la conservación, incluyendo sus puntos fuertes y débiles, y a entender mejor el rol del PSA entre las herramientas de conservación. Probablemente el PSA es la innovación más 
promisoria para la conservación desde Río 1992, pero debe ser validada en escalas mayores y en una mayor variedad de aplicaciones para determinar qué sirve y qué no.

Los principios básicos del PSA que se detallan en este trabajo mostrarán al lector las preguntas que es necesario hacerse antes de diseñar un sistema de PSA; esto corresponde a un nivel intermedio en el proceso de diseño; en consecuencia, no se ofrecerá un manual de campo que indique paso por paso cómo implementar un esquema de PSA. El ejercicio emplea ejemplos tomados del bosque: valoraciones de campo detalladas de Bolivia y Vietnam y experiencias seleccionadas de Ecuador, Indonesia, Costa Rica y Brasil.

Se buscará dar respuesta a las siguientes preguntas específicas: Sección 2 - ¿Cómo se define un esquema de PSA y en qué se diferencia de otros enfoques de conservación? Sección 3 ¿Cómo determinar la medida en que se provee un SA? Sección 4 - ¿Es el PSA más apropiado en unos escenarios que en otros? Sección 5 - ¿ Se da un trueque entre eficiencia y equidad? Sección $6-$ ¿A quién exactamente se le debe pagar? Sección 7 - ¿Deben ser los pagos en efectivo o en especie? Sección 8 - ¿Es el PSA útil para aliviar la pobreza? Sección 9 - Resumen y discusión.

\section{Definición, términos y rasgos claves}

\subsection{Definición}

A mi entender, hasta ahora el PSA no se ha definido formalmente, lo que contribuye a algunas confusiones conceptuales. Para nuestro trabajo de campo en Bolivia y Vietnam, usamos cinco criterios relativamente simples para describir los principios del PSA. Un sistema de PSA es...

- una transacción voluntaria, donde...

- un SA bien definido (o un uso de la tierra que aseguraría ese servicio)...

- es 'comprado' por al menos un comprador de SA...

- a por lo menos un proveedor de SA...

- sólo si el proveedor asegura la provisión del SA transado (condicionamiento).

Según el primer criterio, el PSA se da dentro de un marco negociado y voluntario que lo distingue de las medidas de mando y control. Esto presupone que los proveedores potenciales de SA tienen opciones reales de uso de la tierra, algo que en Vietnam, por ejemplo, no era del caso: los pagos eran parte integral del sistema de mando y control imperante (Wunder et al. 2005).

El segundo criterio establece que lo que se compra debe haber sido bien definido -puede ser un servicio medible directamente (p.e. toneladas adicionales de carbono almacenado)- o usos equiparables de la tierra que, quizás, ayuden a proveer el servicio (p.e. 'la conservación del bosque garantiza la limpieza del agua'). De hecho, la palabra "quizás" esconde importantes incertidumbres científicas y percepciones populares. Los servicios hidrológicos, especialmente, con frecuencia se basan en creencias populares y no en pruebas científicas (Kaimowitz 2004); por ejemplo, 'la cobertura boscosa aumenta la disponibilidad de agua'. Además, hay factores externos que pueden interferir, pues la naturaleza no siempre se porta bien. Por ejemplo, aun si la conservación de los bosques realmente influye en la mayor provisión de agua limpia, este incremento pudiera pasar desapercibido si la frecuencia de tormentas tropicales e inundaciones es alta y, en consecuencia, la calidad del agua resulta afectada. Los pagos que se establecen a partir de relaciones científicamente improbables, o en relaciones probables pero que difícilmente afectarían de manera significativa el resultado deseado, o en mitos, pueden mantenerse durante largo tiempo. En muchos casos, no tenemos el conocimiento que nos permita probar objetivamente cuáles SA ofrecidos son reales y cuáles imaginarios. Sin embargo, podemos suponer que un sustento poco sólido de los SA ofrecidos afectará la sostenibilidad y fortaleza del sistema de PSA: entre menos realista sea la base científica de un esquema de PSA, más expuesto estará a que los compradores cuestionen su racionalidad y dejen de pagar.

En cualquier esquema de PSA debe haber recursos que vayan de al menos un comprador del SA (criterio 3) a al menos un vendedor (criterio 4), aunque con frecuencia la transferencia se da a través de un intermediario. Principalmente, en un esquema de PSA los pagos del usuario deben ser realmente contingentes por un servicio ofrecido de manera ininterrumpida (criterio 5). Por lo general, los compradores del servicio monitorean si se han cumplido las condiciones contractuales; p.e. ¿se maneja la caza, deforestación, agricultura de tumba y quema según lo estipulado en el contrato? En países desarrollados, los aparatos legales y de cumplimiento de las leyes pueden crear las condiciones para pagos únicos que garanticen la provisión futura de SA en sitios permanentes (ver Bayon 2004, Sokolow y Zurbrugg 2003). En los países en desarrollo, esta opción por lo general no existe -y menos aun en las áreas de frontera agrícola donde el cumplimiento de las leyes es débil. Este rasgo implica que, en los trópicos, el PSA debe ser periódico (a menudo con un horizonte infinito) y con monitoreos para determinar el nivel de cumplimiento. Los compradores del SA deben tener la libertad de romper el contrato si no reciben el servicio por el cual pagaron. Por su parte, los vendedores del servicio también pueden estar en búsqueda de contratos flexibles, que puedan rescindirse o modificarse si ocurren cambios en las condiciones. 
¿Cuántos esquemas de PSA encontramos en los trópicos que cumplan con estos cinco criterios básicos? Nuestro estudio en dos países (Bolivia y Vietnam) demostró que ni un solo esquema satisfizo todos los cinco criterios, aunque varios cumplen con más de uno (Robertson y Wunder 2005, Wunder et al. 2005). Por ejemplo, se hacían pagos por la protección ded cuencas hidrográficas, pero no había libertad para decidir sobre el uso del suelo (criterio 1). La naturaleza del servicio ofrecido con frecuencia era poco clara (criterio 2). Por lo general, el dinero provenía de donantes y no de los usuarios del servicio (criterio 3). Otras veces, se cobraba a los usuarios pero no se pagaba a los proveedores del servicio (criterio 4).

No obstante, el criterio más difícil de satisfacer es el 5: el condicionamiento. El monitoreo en muchas iniciativas es poco riguroso, o no se monitorea del todo; los pagos se otorgan al inicio, en vez de periódicamente. Los pagos se hacen de buena fe y no como resultado del monitoreo de la provisión real del servicio. El enfoque empresarial que refleja el sistema de pagos contingentes para la conservación creó resistencia en todos los países estudiados. En resumen, si bien el número de iniciativas de PSA en los trópicos es alto -LandellMills y Porras (2002) revisaron 287 esquemasverdaderamente hay pocos que responden al concepto teórico desarrollado en la bibliografía y descrito en la definición que antes diéramos.

Ahora bien, si nuestro trabajo de campo encontró tan pocos 'PSA verdaderos', ¿se debe esto a que la definición es, simplemente, demasiado estrecha? Históricamente, muchos esquemas de subsidios a la reforestación y conservación de suelos se justificaban en parte como servicios ambientales, aunque por lo general se presumía -no se monitoreaba- la provisión del servicio. El PSA también pudiera definirse simplemente por las palabras que componen el concepto; así, cualquier 'pago' que de alguna manera busca promover 'servicios ambientales' pudiera ser PSA. En consecuencia, además de los subsidios a la reforestación y conservación de suelos, los salarios de los guardas que cuidan áreas protegidas, o de gente que trabaja en proyectos de conservación y ciertamente todos los PICD, calificarían como PSA. Si, a pesar de todo, prefiero mantener la anterior definición es porque creo que estos cinco principios representan algo nuevo: un enfoque más directo que merece ser probado bajo sus propios términos, antes de incorporarse a la gran colección de herramientas ambientales probadas. El evaluar casos específicos para determinar los diferentes grados de cumplimiento de los cinco criterios -aunque algunas veces es una tarea con diferencias sutiles- puede servir como indicador de la medida en que estos casos realmente reflejan el principio subyacente al PSA.

\subsection{Terminología}

¿Qué términos se han usado para describir este tipo de mecanismo innovador? En el Recuadro 1 se resumen cuatro términos que describen el mecanismo de remuneración (la ' $P$ ' de PSA): pagos, mercados, gratificación, compensación. Como se ve en detalle en el Recuadro 1, la escogencia del término depende de lo que se espera del mecanismo: ¿Se busca la interacción competitiva entre múltiples agentes ('mercados'), el precio justo o equitativo por los servicios ofrecidos ('gratificación', o el resarcimiento por un costo que asumió quien ofrece el servicio ('compensación')? Esto claramente tiene que ver con preguntas claves sobre cuáles situaciones merecen una remuneración, a quién, en qué 'moneda' y cuánto; estas preguntas son el objeto de análisis de este documento. Los términos, además, pueden activar asociaciones políticas e ideológicas que, a la vez, influyen en si el mecanismo se implementa o no (Wunder y Vargas 2005). Asumimos que 'pago' es el término más genérico y con menos tinte ideológico; no obstante, la selección del término más apropiado depende de cada caso específico.

La ' $\mathrm{S}$ ' probablemente sea el elemento menos controversial, pues hay consenso en cuanto a los 'servicios' como beneficios de la naturaleza no materiales ni extractivos. Un factor de duda es cómo clasificar a los productos 'verdes' certificados que se producen junto con un servicio ambiental. Algunas evaluaciones del valor global de los PSA incluyen por completo el valor de estos productos (Scherr et al. 2004). En este trabajo, consideramos únicamente el valor del 'premium verde'; es decir, el valor de la diferencia entre los bienes producidos de manera convencional y los producidos de forma ecológica, que genuinamente puede atribuirse a los SA.

Finalmente, la ' $A$ ' de PSA también ha sido objeto de discusión: ¿tiene que ver con servicios del 'ambiente' o del 'ecosistema'? En este trabajo asumimos que ambos son de naturaleza diferente. El último probablemente sea más integral, lo que implica que múltiples servicios no siempre se pueden separar en sus elementos constitutivos (Scherr et al. 2004). Sin embargo, para nuestros fines, la diferencia es mínima.

\subsection{Rasgos claves}

¿Qué rasgos distinguen el PSA de otros enfoques de conservación? El PSA ya antes ha sido comparado con los PICD; sin embargo, se requiere de una evaluación más amplia que incluya una comparación con otros instrumentos de conservación. En la Figura 1 se jerarquiza una serie de enfoques de conservación con base en dos criterios: primero, el grado en el que dependen de incentivos económicos y segundo, el grado en el que se enfocan en la conservación 
Recuadro 1. Terminología empleada en la remuneración de servicios ambientales

1. 'Pago por SA'. - Este es el término más general; sin embargo, tiene una clara asociación monetaria que puede generar resistencia ideológica (Wunder y Vargas 2005) y, localmente, puede crear conflictos con la opción de pagos en especie (Sección 7).

2. 'Mercados para SA'.- Este es un término ampliamente usado por el Grupo Katoomba y IIED, entre otros. El término incluye no sólo un rol primordial para los incentivos económicos, sino además sugiere la existencia de múltiples actores, opciones y algún grado de competencia. Estos mercados existen en algunos países desarrollados, pero en los países en desarrollo están lejos de alcanzarse. Los mecanismos de mercado enfrentan restricciones generales en los países en desarrollo; además, la naturaleza local de los ecoservicios con frecuencia limita la competencia, por lo que se crean monopolios de facto. Por ejemplo, los usuarios urbanos del agua no pueden escoger entre diferentes finqueros aguas arriba, ni una reserva privada que busca proteger una especie endémica puede simplemente cambiar de área. Los esquemas de un solo comprador (monopsónicos) son muy comunes: servicios de agua potable, fábricas de cerveza, empresas eléctricas, operadores de turismo. En consecuencia, muchos esquemas no son 'mercados', sino simplemente acuerdos bilaterales entre un vendedor y un comprador. Los mercados tienen algunos rasgos deseables en términos de alocacación de los recursos de la sociedad, por lo que en algunos casos se convierten en objetivos deseables a largo plazo. Sin embargo, cuando los costos de transacción del esquema son altos -como en la protección de cuencas- el contar con múltiples compradores y vendedores pudiera ni ser tan atractivo. Nuestra investigación en Bolivia, Vietnam y otros sitios demostró que los mercados pueden llegar a ser ideológicamente asociados con el neoliberalismo, con lo que se crea una alienación política que va en contra de la promoción del PSA (Wunder y Vargas 2005).

3. 'Gratificación por SA'. - Este término posee una connotación de premio y de hacer justicia a quienes proveen los servicios: quienes garantizan la existencia de un beneficio deben ser premiados por ello. Este concepto ha sido empleado por el programa RUPES (Gratificación a familias pobres de las zonas altas por servicios ambientales) en Asia (van Noordwijk et al. 2004). Sin embargo, su connotación general pudiera crear expectativas excesivas, pues es probable que no se encuentren compradores para servicios que no son de mucho valor, o que están poco amenazados (Sección 5).

4. 'Compensaciones por SA'. - Este ha sido utilizado como marco comparativo (Rosa et al. 2003). Se refiere propiamente a un costo directo o de oportunidad que favorece al proveedor del servicio, quien por una justificación moral y racionalidad social debiera ser compensado. La 'gratificación' implica que todos los que ofrecen el servicio deben recibir un pago; la 'compensación', en cambio, restringe el pago a aquellos que han hecho gastos para mantener el servicio; quienes no hayan tenido costos no deben ser compensados. El término resulta poco apropiado cuando el proveedor busca no sólo compensar los costos en los que incurrió, sino también obtener ganancias que exceden sus costos. En un sentido estricto, la compensación pura de costos, sin 'superávit del proveedor', no tendría un impacto en el alivio de la pobreza de los beneficiarios del PSA.

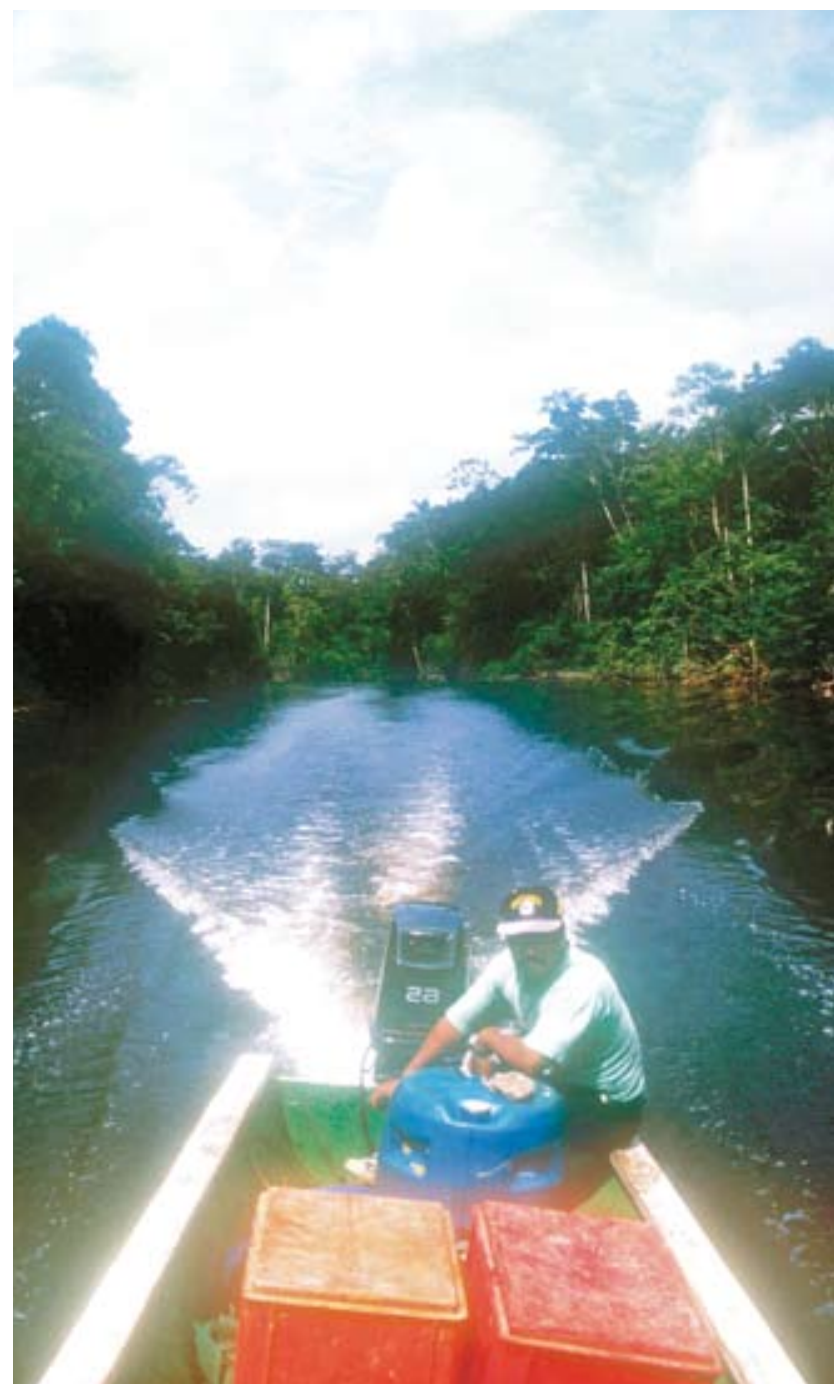

Poblador de Zancudo trabajando como botero para una empresa de turismo. La comunidad de Zancudo recibió compensaciones en especie de parte de la empresa Transturi por no cazar en una zona de alta visitación turística en Imuya, Reserva de Vida Silvestre de Cuyabeno, región amazónica norte del Ecuador (Foto: Sven Wunder). 


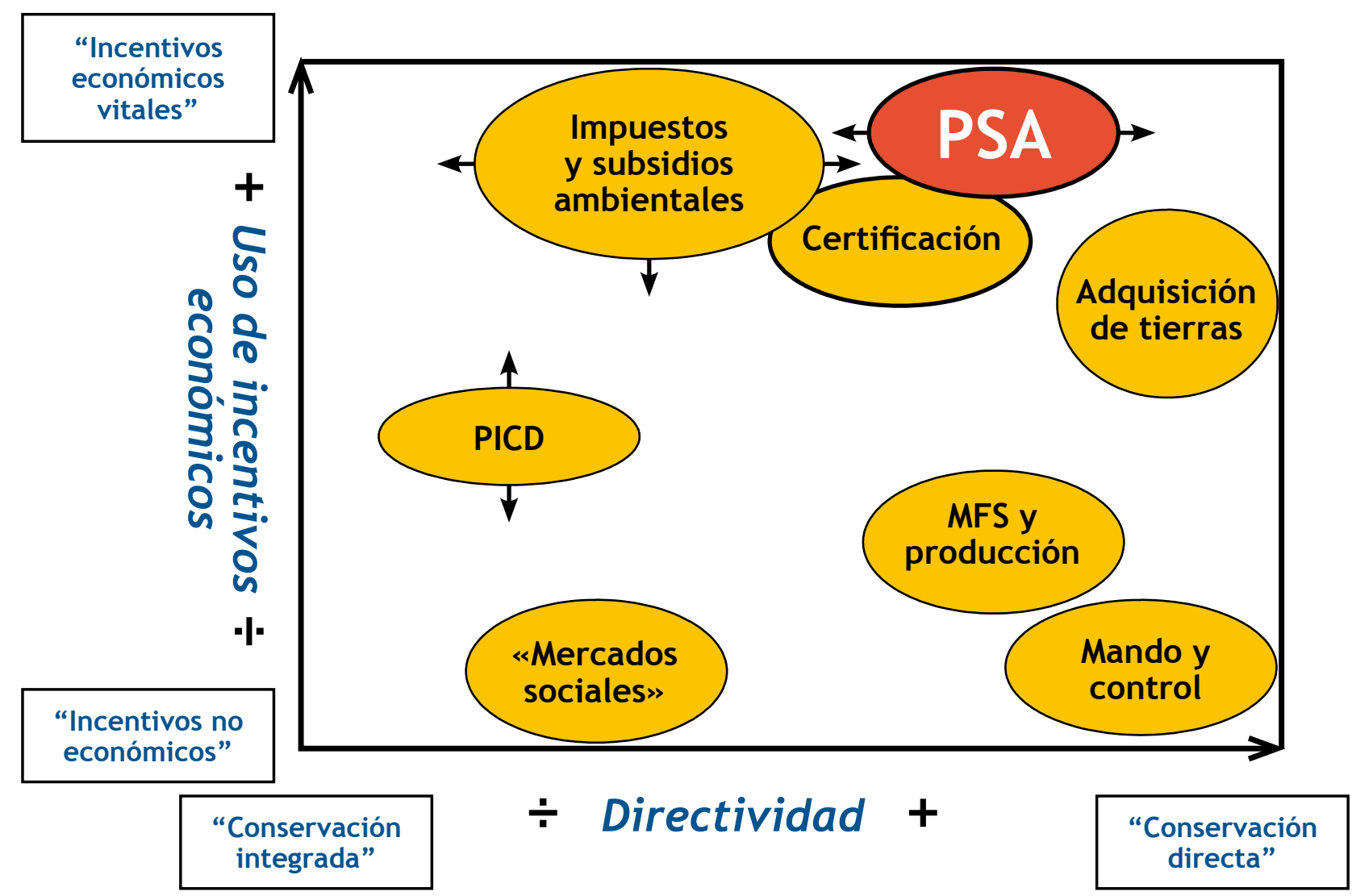

Figura 1. Comparación del PSA y otros enfoques de conservación

por sí misma y no como parte de otros enfoques de desarrollo. Nótese que los enfoques descritos no son mutuamente excluyentes, sino que podrían combinarse en diferentes estrategias de conservación.

Las normas de mando y control (que incluyen la creación de áreas estrictamente protegidas) buscan, directamente, proteger el recurso sin el apoyo de incentivos económicos -excepto cuando la corrupción hace que las normas se conviertan en impuestos no oficiales de facto. Estas normas se ubican en la esquina sureste del diagrama y contrastan fuertemente con el carácter flexible y voluntario del PSA. Sin embargo, el PSA puede coexistir, y aún impulsar, medidas de mando y control; tal es el caso del Protocolo de Kyoto, que pre-condiciona los mercados de mitigación de carbono. El manejo forestal sostenible (MFS) $\mathrm{y}$ otros medios similares que tratan de mejorar el uso de los recursos buscan directamente la conservación influyendo en los procesos de extracción y producción. Las modificaciones técnicas son el principal instrumento, aunque los incentivos económicos y los mecanismos de desarrollo también pueden influir.

En la esquina suroeste, se ubican los PICD que, por naturaleza, son lo opuesto de 'directo', no son contingentes y explícitamente integran la conservación y el desarrollo; sus efectos deseados son 'la conservación por distracción' y 'a menor pobreza, menor degradación’. Sus esfuerzos integrales incluyen la construcción de capacidad institucional local, la generación de beneficios para 'comprar' la buena voluntad local hacia la conservación y para influir en las políticas gubernamentales. Los incentivos económicos en los PICD juegan un rol variable. A diferencia del PSA, los PICD requieren inversiones en formas alternativas de producción; son proyectos 0 programas que pretenden intervenciones holísticas (a menudo, paternalistas). En contraste, el PSA se refiere más bien a transacciones sensibles a las dinámicas de desarrollo local, pero sin pretensiones paternalistas; se trata de vender y comprar un servicio para lograr un uso de la tierra más racional. No obstante, se podría pensar en formas híbridas, como proyectos integrales financiados de manera contingente (Sección 9).

Adyacente a los PICD tenemos los mercados sociales (Heyman y Ariely 2004). Estos abarcan sistemas de reciprocidad e intercambio de favores en diferentes escalas sociales. Por definición, estos sistemas son no monetarios -los críticos argumentan que la introducción de proyectos de PSA pudiera echar a perder los mercados sociales (Sección 6). Estos mercados por lo general son sistemas tradicionales que han evolucionado localmente en el tiempo. Algunos de los aspectos que impulsan la conservación son la persuasión moral, la presión social o favores prometidos; todos estos factores se relacionan con los sistemas sociales integrados y los procesos de desarrollo, y no con la conservación directa. 
Obviamente, el PSA pertenece a la familia de enfoques que hacen uso de los incentivos económicos (parte norte del diagrama); de hecho, los incentivos son fundamentales en el PSA. En este sentido, el PSA se parece a los impuestos y subsidios basados en el ambiente. Pero el enfoque del PSA por 'comprar la conservación' de manera contingente es más directo que la mayoría de impuestos y subsidios, que más bien buscan cambios más amplios en los patrones de producción y uso de los recursos. Para algunos, la obtención de mejores precios con la certificación de productos se traslapa con el PSA (ver más adelante en esta misma sección). El programa 'IVA ecológico' practicado en varios estados brasileños es otro caso donde se empata el PSA con instrumentos fiscales ambientales: se transfieren impuestos del gobierno federal a las municipalidades como premio por el tamaño y calidad de las áreas conservadas (May et al. 2002, Grieg-Gran 2000).

La adquisición de tierras para conservación y otras medidas similares, como pagar a los concesionarios madereros para que no hagan uso de la concesión, buscan eliminar a actores ambientalmente problemáticos. El PSA, por su parte, trata de negociar con esos actores. El PSA normalmente no implica cambios en la tenencia de la tierra, por lo que puede resultar más barato y más adaptable, no implica la expulsión de los pobladores locales y el comprador no tendría que preocuparse por hacer valer sus derechos. No obstante, la implementación y ejecución de un esquema de PSA pudiera, con el tiempo, requerir mayores costos de transacción (negociación, monitoreo, etc.) que la compra de tierra (una única vez), y siempre existe el riesgo de que el proveedor cancele o viole el contrato de PSA. La compra de tierras es directa y no se integra con una dimensión de conservación - desarrollo posterior. A la vez, en la medida en que los ingresos generados por el PSA cambian la dinámica local de subsistencia a través de ingresos, consumo, mercados de capital y de mano de obra, esto puede fortalecer o debilitar la conservación ya sea porque afecta la sostenibilidad del contrato de PSA, o por efectos ambientales colaterales e inesperados. Esta retroalimentación indirecta, generada por la dinámica de desarrollo del PSA, a menudo es olvidada por quienes ven el PSA puramente como 'conservación directa'.

\subsection{Tipos de PSA}

Los esquemas de PSA claramente se distinguen de otras herramientas de conservación, pero internamente son también muy diversos unos de otros. A continuación se analizan tres diferentes tipos de esquemas: basados en área vs. basados en productos, públicos vs. privados y de uso restringido vs. realce productivo.
Primero, los esquemas de PSA difieren en cuanto a los vehículos usados para lograr los efectos de conservación o restauración. El tipo más común son los esquemas basados en el área; en estos, el contrato estipula usos equiparables de la tierra y/ o de los recursos para un número predeterminado de unidades de terreno. Ejemplos son las concesiones para la conservación (Niesten et al. 2004, Hardner y Rice 2002), servidumbres, cuencas contratualmente protegidas o plantaciones para el secuestro de carbono (Smith y Scherr 2002). En orden de importancia siguen los esquemas basados en productos, mediante los cuales los consumidores pagan un 'premium verde', el cual es un sobreprecio para los esquemas de producción certificados como amigables con el ambiente, y especialmente con la biodiversidad (Pagiola y Ruthenberg 2002). El sobreprecio puede otorgarse a un producto que respeta el valor de uso o no uso de hábitats prístinos (p.e. ecoturismo, extracción de caucho), para formas de producción agroecológica que preservan niveles de SA relativamente altos (p.e. café bajo sombra, agricultura orgánica), o para métodos de producción de SA que empleen las mejores prácticas para minimizar los impactos ambientales negativos (p.e. madera certificada, propuesta de certificación de la producción de soya y ganado en Brasil).

Segundo, los esquemas de PSA también difieren en cuanto a quiénes son los compradores. En esquemas públicos, como en Costa Rica, México y China, el estado actúa en defensa de los compradores de los SA mediante el cobro de impuestos y solicitud de donaciones para pagar a los proveedores. Los esquemas privados, por su parte, se enfocan más en las necesidades locales (p.e. los esquemas de cuencas en Pimampiro-Ecuador, Valle del CaucaColombia, Santa Rosa-Bolivia, y básicamente todos los esquemas de carbono), y los compradores pagan directamente. Los esquemas públicos por lo general son de mayor alcance y gozan de la legitimidad estatal, lo que no es evidente en los esquemas privados. Por otra parte, los esquemas públicos pueden verse saturados de objetivos secundarios que buscan seducir a los votantes y no ofrecer servicios ecológicos propiamente dichos; son menos flexibles en cuanto a los vendedores estratégicos de SA, y tienden a ser menos eficientes al asegurar la provisión de SA (Sección 3).

Finalmente, los esquemas de PSA de uso restringido premian a los proveedores por la conservación (incluyendo la regeneración natural), por equiparar la extracción de recursos y el desarrollo de la tierra, o por preservar zonas como hábitats protegidos. Aquí los dueños de la tierra reciben un pago por los costos de oportunidad de la conservación y por sus esfuerzos de protección activa contra amenazas externas (Hardner y Rice 


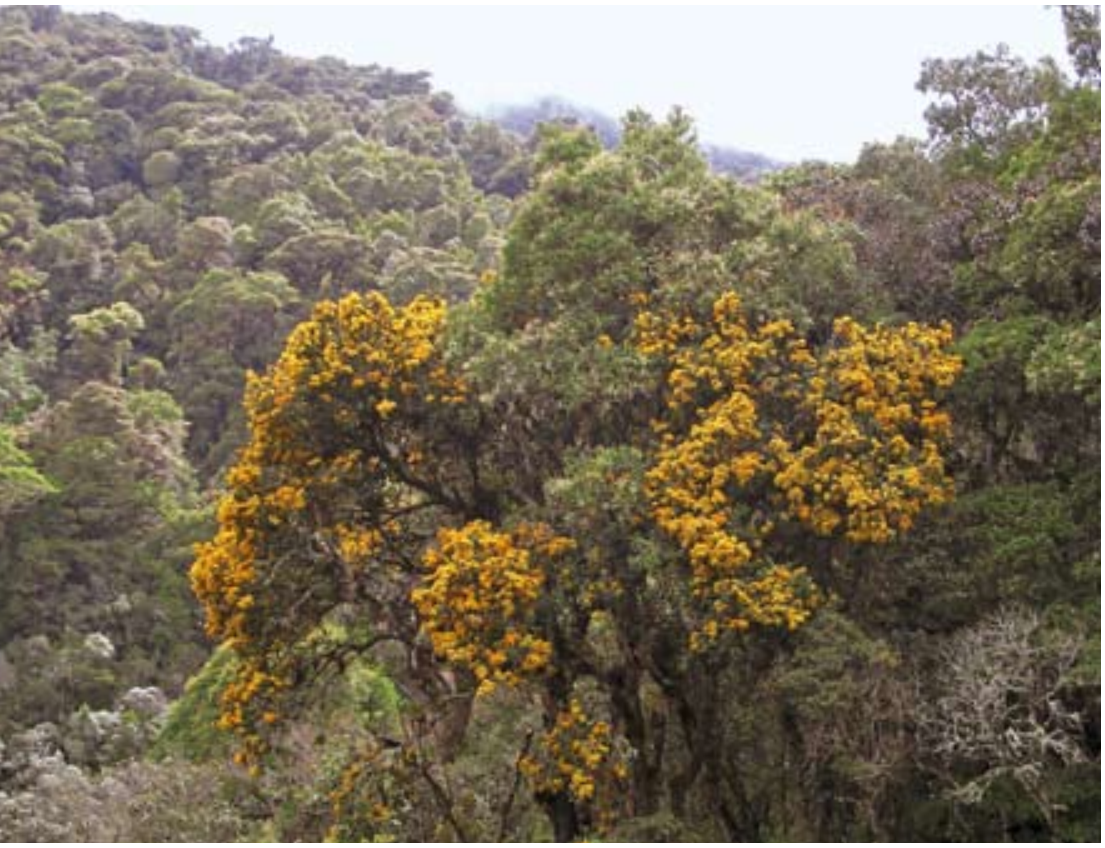

Bosque nublado protegido por el esquema de PSA de la cuenca de Pimampiro, región norte del Ecuador (Foto: Sven Wunder).

2002). En contraste, en los esquemas de 'realce productivo' el PSA busca restaurar los SA en un área dada; por ejemplo, (re)plantando árboles en paisajes degradados y deforestados. Aparte de los costos de oportunidad y de protección, el PSA también puede compensar los costos directos de establecer SA, a menudo mediante inversiones en sistemas agrícolas (Pagiola et al. 2004). Si el PSA es una renta económica por básicamente "no hacer nada", o si es por lo menos un premio parcial por mejorar los SA activamente, tiene algunas implicaciones en el empleo rural (Sección 8).

\section{3. ¿Cómo evaluar la eficiencia del PSA?}

Si uno va al mercado a comprar pescado para el almuerzo, eventualmente su gusto puede ser mejor o peor de lo esperado, pero siempre será basicamente lo que uno esperaba a cambio de su dinero. Cuando uno compra un servicio ambiental, no es tan claro si uno va a recibir el producto por el que pagó. Puesto que el SA se ofrece a través del tiempo, siempre es conveniente considerar qué pasaría sin el esquema de PSA; o sea que es necesario pensar en algunas líneas base hipotéticas. La primera pregunta -y la más importante- es si el esquema de PSA tiene un efecto lo bastante grande y acumulativo en función de la línea base: ¿Hace realmente la diferencia? Este aspecto de 'adicionalidad' ha sido muy discutido por el Mecanismo de Desarrollo Limpio (MDL) del Protocolo de Kyoto. Actualmente, se acepta que sólo la reforestación y la aforestación cumplen con ese principio de adicionalidad y, por lo tanto, son los únicos elegibles para recibir créditos de carbono. La protección de los bosques que desaparecerían si no reciben un PSA no califica. La Figura 2 ilustra tres escenarios básicos de línea base o puntos de partida.

Las reglas actuales del MDL son un ejemplo de la línea base estática (a) donde se supone que la cantidad de carbono almacenado en los bosques permanecería constante en relación con un escenario histórico. La diferencia se atribuye, entonces, a intervenciones específicas que califican para créditos de carbono. Los críticos alegan que en muchos países tropicales la deforestación es parte integral del desarrollo, lo que implícitamente significa una línea base dinámica y en declinio (b). La detención, o aun una disminución de la deforestación ('deforestación evitada') calificarían para créditos de carbono y de adicionalidad. Sin embargo, países o regiones en una etapa avanzada de su proceso de 'transición forestal' también logran mejorar su cobertura boscosa como resultado de prácticas de desarrollo que revaloricen el bosque y 'economicen' los suelos, aun sin intervenciones específicas. Un ejemplo de esta línea base de mejoramiento (c) es Costa Rica, donde a principios de la década de 1990 (entre 1987 y 1996/97) se inició un proceso de recuperación de la cobertura boscosa; es decir, antes de que se implementara el sistema de PSA a partir de 1996.

Esto demuestra que la selección de la línea base es de vital importancia para la eficiencia del PSA. Por ejemplo, el sistema de PSA de Costa Rica se basa en un punto de partida estadístico, pero si en realidad el bosque aumentara aun sin PSA, esto significa que el sistema estaría pagando por reforestación o conservación que de todas maneras se hubiera dado; esta sospecha se confirma con estudios de casos de dueños de bosque que reciben PSA por sus propiedades de recreo, donde es muy poco probable que eliminen o degraden el bosque (Miranda et al. 2003). Por otro lado, las reglas del MDL obvian oportunidades importantes para disminuir la pérdida de bosques mediante incentivos económicos, debido al uso de líneas base rígidas y estáticas. Si se adopta un punto de partida equivocado se puede disminuir la eficiencia del PSA, o en el peor de los casos, perder todo el dinero invertido: si no se logra un cambio real en la conducta, no se producirán servicios ambientales adicionales.

Otros dos conceptos de eficiencia del PSA son relevantes cuando el alcance intrínseco del SA excede en el tiempo o en el espacio el alcance de la intervención específica. Esto es de primordial importancia para el secuestro de carbono, un servicio global y de largo plazo, que se mejora con una serie de intervenciones específicas en el tiempo y el espacio. Si un esquema de PSA por carbono financia la reforestación en un área 
dada, pero esto causa directamente problemas de deforestación en un área vecina, el esquema de PSA, entonces, sufre un problema de fuga: si bien se logró una alta adicionalidad en el área del proyecto, no fue así en el área circundante. Si al finalizar el esquema de PSA todos los árboles reforestados se cortan para leña, su permanencia habrá sido muy poca. Fuga y permanencia son también conceptos relevantes para los objetivos de biodiversidad, valores estéticos y cuencas hidrográficas, dependiendo de qué tan centrados estén estos objetivos en el tiempo y el espacio, en comparación con el alcance de intervenciones específicas de PSA.

En la definición del punto de partida y en la evaluación de la adicionalidad hay que considerar varios asuntos prácticos. Es conveniente combinar la implementación con la investigación y la recuperación sistemática de datos, tal como se dio en el proyecto RISEMP en Colombia, Costa Rica y Nicaragua (Pagiola et al. 2004). Si sólo se observan los resultados en áreas donde se aplica el pago, no sería posible discernir el impacto del PSA independiente de variables no consideradas, como ubicación del receptor del pago, escolaridad, actitudes hacia la conservación, etc. La selección al azar de los beneficiarios podría ayudar a controlar este sesgo (R. Godoy, com. pers. Universidad de Brandeis, EE.UU., 7 abril 2005). En el proyecto RISEMP se designaron grupos para controlar no sólo si los pagos tenían lugar, sino además si junto con el pago se daba asistencia técnica (J. Gobbi, com. pers. Turrialba, Costa Rica, CATIE, 9 febrero 2005).

\section{4. ¿Para qué escenarios de uso de la tierra se emplea el PSA?}

A la luz de la literatura que aboga por los esquemas de PSA (Ferraro y Kiss 2002, Ferraro y Simpson 2002, Ferraro 2001), uno podría pensar
Depósitos de carbono

en el bosque A) Línea base estática

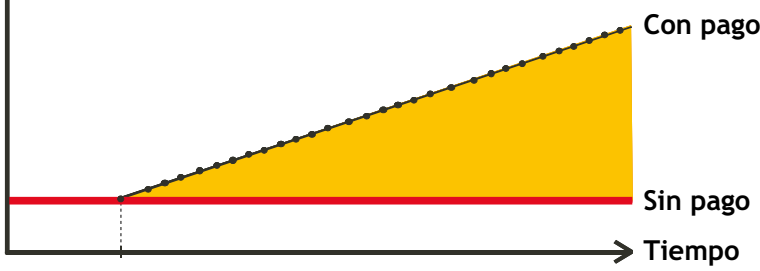

PSA

Depósitos

de carbono

en el bosque

B) Línea base de deterioro

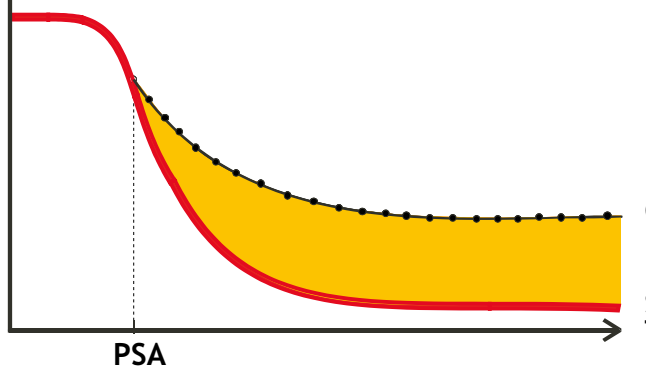

Con pago

Sin pago Tiempo

Depósitos

de carbono en el bosque

C) Línea base de mejoramiento

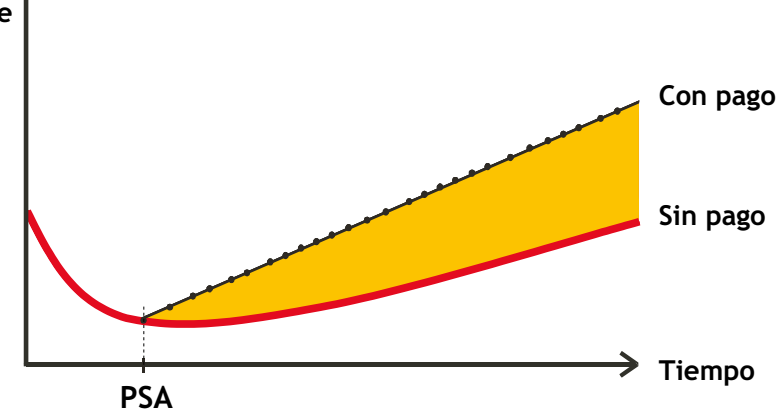

Adicionalidad

Figura 2. Tres diferentes líneas base para el PSA

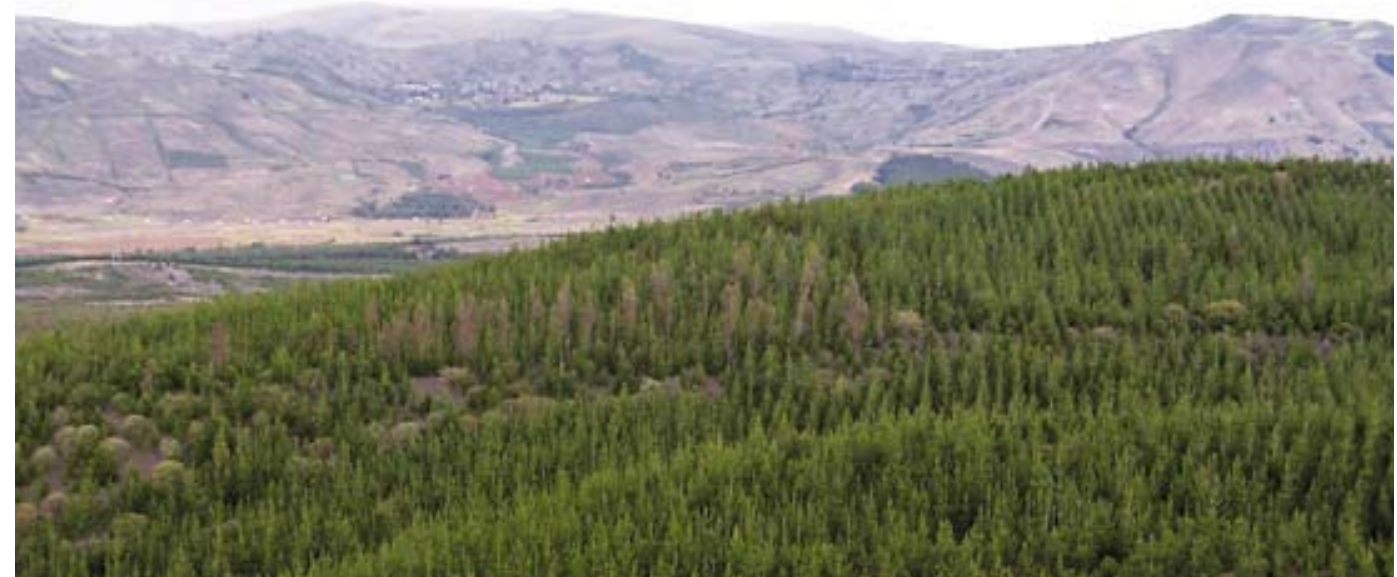

Plantaciones de pino en terrenos comunales establecidas por el programa de secuestro de carbono de PROFAFOR (Programa de forestación para la absorción de emisiones de dióxido de carbono en Ecuador). Altos Andes cerca de Guamote, sur de Ecuador (Foto: Sven Wunder). 


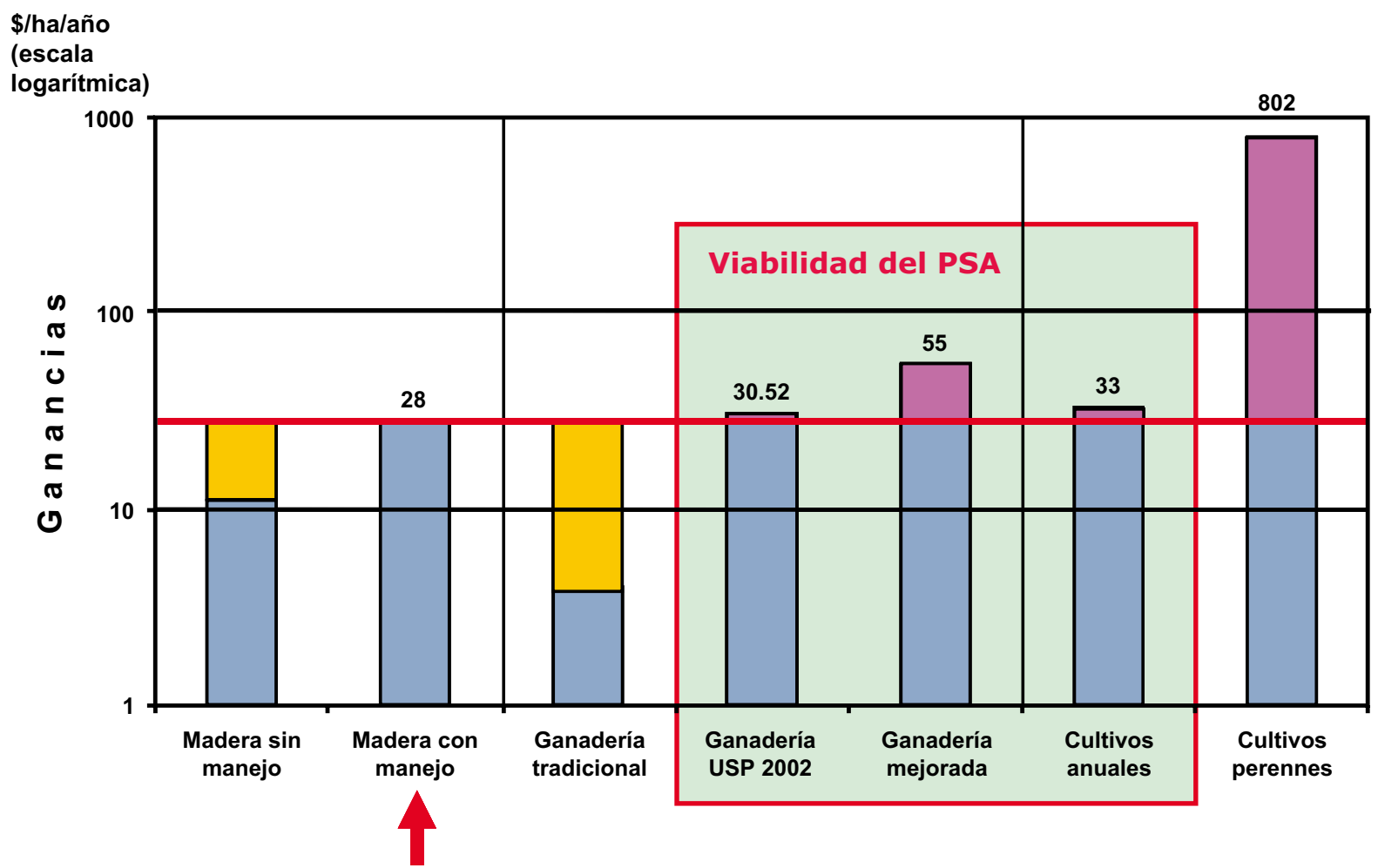

Figura 3. Rentabilidad comparada de usos de la tierra en Paragominas, Brasil

Fuentes: Almeida y Uhl (1995), Margulis (2003)

que este tiene una ventaja absoluta por encima de otros enfoques, en especial de los PICD. Pero, como antes se dijo, también pueden existir otros instrumentos cuya eficiencia para la conservación variaría con el contexto. El costo de oportunidad de la conservación -es decir, el rendimiento de usos alternativos de la tierra, es un factor discriminante que determina dónde se puede aplicar el PSA. La Figura 3 ofrece un ejemplo numérico de la rentabilidad del uso de la tierra en Paragominas, Amazonia brasileña, el cual analizaremos a continuación.

Con fines de simplificación, supongamos que diferentes compradores han llegado juntos a la conclusión de que el manejo del bosque para la producción de madera es el uso de la tierra más deseable en Paragominas, ya que maximiza diferentes SA y garantiza un ingreso productivo mínimo a los dueños de la tierra. En consecuencia, han decidido aunar recursos para financiar un esquema de PSA que ofrezca incentivos por cambiarse a la producción de madera bajo manejo. En comparación con la rentabilidad neta de este uso (US\$28/ha/año -línea horizontal en Fig. 3), otras actividades tienen retornos económicos más altos o más bajos. Entonces, ¿cuáles usos sería posible sustituir con un esquema de PSA?

Las actividades que tienen retornos más bajos (madera sin manejo, ganadería tradicional) es poco probable que sean influenciadas por un subsidio por manejar la producción de madera.
Si pudieran, los dueños de la tierra ya se hubieran cambiado a una actividad que ofrece una rentabilidad mayor; en consecuencia, hay otros factores que les impiden hacer el cambio (acceso a crédito, tecnología, infraestructura, conocimiento, etc.) que no se relacionan directamente con la rentabilidad recurrente del uso de la tierra.

En el otro extremo del espectro, los cultivos perennes reciben US $\$ 402 / \mathrm{ha} / \mathrm{año}$-un retorno económico por hectárea al menos 28 veces más alto que la madera manejada. Hacer que los productores cambien los cultivos perennes por producción de madera exigiría un subsidio astronómico, el cual excedería las posibilidades de financiamiento del esquema y el valor económico del incremento obtenido del SA. Sin embargo, para las actividades que son marginalmente más rentables que el uso deseado (ganadería mejorada y cultivos anuales en el 'triángulo de viabilidad' de la Fig. 3), un subsidio podría modificar el punto de equilibrio e inducir el cambio deseado hacia la forestería sostenible.

Por inferencia, un sistema de PSA será más efectivo, en términos de costos, en el rango medio de actividades marginalmente más rentables que el uso de la tierra deseado. Para actividades menos rentables, el PSA probablemente sea irrelevante, y para actividades mucho más rentables, lo limitado de los recursos impide que se les otorgue la compensación necesaria. 
Obviamente, hay que tener cuidado al usar este ejemplo para representar el complejo mundo real. Los productores no sólo se preocupan por la rentabilidad promedio anual, sino también por otros factores como riesgo, fluctuaciones de precios, retornos esperados a futuro, legalidad del uso y seguridad de la tenencia. Donde hay mucha tierra, como en la Amazonía, también se pueden interesar por el retorno por unidad de mano de obra o de capital invertida, más que por la unidad de terreno. Los compradores de SA que quieren proteger servicios existentes y amenazados en esquemas de uso restringido (p.e. reservas de la biodiversidad) debieran ser capaces de anticipar amenazas emergentes y alzas en los costos de oportunidad; si únicamente reaccionan a los cambios que ya se han dado, los servicios pudieran perderse irremediablemente (ver la siguiente sección).

Por otra parte, este ejemplo simple nos enseña algunas lecciones prácticas importantes. Por ejemplo, Proambiente, un floreciente programa de PSA en Brasil, entre otras actividades promueve el establecimiento de cultivos perennes mediante créditos subsidiados por el PSA. Pero, como lo muestra la Figura 3, la rentabilidad promedio de los cultivos perennes es extremadamente alta; entonces, es poco probable que la reducción de costos de capital recurrente y las tasas de rentabilidad marginalmente más altas mediante el PSA hagan la diferencia para cambiar el uso de la tierra. Los cultivos perennes se podrían promover mejor mediante la reducción del riesgo a enfermedades, las fluctuaciones de precios, la restricción de créditos y otras barreras que restringen el acceso a esa práctica. Es probable, entonces, que el enfoque de proyectos integrados tradicionales enfocados en múltiples restricciones sea más apropiado que el PSA para la adopción de prácticas de cultivos perennes.

Contrario a la creencia común, antes de establecer un PSA por lo general no es necesario hacer una valoración económica completa de los servicios del ecosistema por parte de los compradores, ni un estudio económico de la rentabilidad del sistema de la finca por parte del proveedor. En principio, cualquier precio que las dos partes negocien puede ser 'el precio correcto', tan correcto como el precio que pagué por el pescado en el mercado. Para el secuestro de carbono ya existe un precio de referencia en el mercado. Sin embargo, algunos cálculos adicionales pueden ciertamente ayudar a cada parte a fortalecer su posición negociadora, o aun a anticipar si un esquema de PSA es una opción realista o no.

Un ejemplo puede ilustrar esto. En un esquema piloto de PSA en Santa Rosa, zona de amortiguamiento del Parque Nacional Amboró de Bolivia, se ofreció un PSA anual relativamente bajo (pago en especie de US\$7/ha/año) a los propietarios por preservar sus bosques para la conservación. Los costos de oportunidad variaban con la pendiente, fertilidad del suelo y acceso, pero correspondían a un orden de magnitud más alto. Si las tasas de PSA eran tan poco competitivas, seguramente nadie se interesaría por el esquema de conservación. Sin embargo, algunos finqueros se interesaron, principalmente porque les ofrecía dinero en efectivo por mantener un bosque que de todas formas pensaban conservar. Si bien el esquema ha logrado avances importantes en la promoción de los principios básicos del PSA, ha ganado poco en la adicionalidad de SA, al menos hasta ahora (Robertson y Wunder 2005).

En una situación como esta, una determinación básica del costo de oportunidad puede ayudar a definir tasas competitivas de PSA y a encausar los recursos limitados a aquellas áreas donde realmentehagan la diferencia. Comolodemuestran los resultados parciales de una investigación en curso en Costa Rica, se puede lograr una mayor eficiencia si se cambia el simple pago por área a tarifas diferenciadas en el espacio y ajustadas al potencial de provisión de SA y a los costos de oportunidad de diferentes paisajes boscosos ( $T$. Wünscher, com. pers. Turrialba, Costa Rica, CATIE, 10 febrero 2005) - aunque eventualmente podría haber obstáculos políticos y económicos para implementar pagos diferenciados en un esquema público.

\section{5. ¿Eficiencia o equidad?}

En los círculos de conservación y desarrollo rural, muchos ven el PSA como una fuente de justo reconocimiento a los pobres rurales que cuidan el ambiente y continuamente 'producen' SA, hasta ahora gratuitamente (Shilling y Osha 2003, Rosa et al. 2003, van Noordwijk et al. 2004). Sin embargo, desde el punto de vista de la eficiencia, sólo aquellos que constituyen una amenaza real a la provisión de SA deberían recibir un pago. Regresemos a la Amazonia brasileña por un ejemplo.

Primero, los remotos estados federales de Amazonas y Amapá recientemente han declarado la protección de grandes áreas de bosque, y los gobiernos estatales esperan conseguir recursos de la cooperación internacional para apoyar sus políticas de conservación con recursos de tipo PSA. No obstante, las tasas de deforestación en la mayoría de esas áreas remotas siguen siendo muy bajas, lo que quiere decir que el desarrollo de la frontera agrícola no ha llegado hasta allí. ¿Por qué habrían de pagar los compradores por la conservación de un bosque que no está amenazado -que de todas maneras se va a conservar (adicionalidad insignificante)? Si la presión por el uso de la tierra se da muy lejos de allí, ¿qué tan previsora debiera ser una iniciativa de PSA? 
Segundo, el estado de Mato Grosso está en el otro extremo del espectro, pues allí se promueve agresivamente la expansión de la ganadería y el cultivo de soya. Las altas tasas de deforestación reflejan serias amenazas de cambio de uso y altos costos de oportunidad para la conservación, especialmente por la gran rentabilidad del frijol de soya. El contexto económico, biofísico y político induce a una rápida conversión del bosque. Por lo tanto, hay varias buenas razones para intervenir pero, ¿se podría revertir el proceso, aun con un PSA a gran escala? O bien, ¿están el sistema y sus fuerzas económicas ya muy enfocados hacia un escenario donde los bosques van a disminuir rápidamente, limitado sólo por la escasez de capital, de infraestructura vial, de tiempo, y posiblemente restricciones legales? ¿Habrá mayores esperanzas para los conservacionistas en las medidas de mando y control, como la puesta en vigencia de restricciones legales que exigen que se mantenga un porcentaje mínimo de bosque en las fincas?

Tercero, un estado federal, como el rico y lejano Acre, constituye un ejemplo intermedio. Su autodeclarado Governo da Floresta (Gobierno del Bosque) constituye una práctica innovadora de la legislación socioambiental, con un movimiento de base proactivo. Esta práctica ha llamado la atención de los donantes externos. Al mismo tiempo, factores económicos emergentes, como la construcción de carreteras que enlazan a Acre con los vecinos Perú y Bolivia y la demanda cada vez mayor por carne y madera, aumentan la presión sobre los bosques y aceleran las tasas de deforestación. ¿Es este contexto intermedio, con grandes amenazas evidentes y costos de oportunidad cada vez más altos, el escenario más favorable para la implementación del PSA?

Obviamente, no hay respuestas fáciles -y mucho menos porque los tres estados poseen a lo interno una gran variedad de subescenarios. Los compradores de biodiversidad deben mantener un portafolio diversificado que preste atención a las amenazas actuales y futuras. Los esquemas de PSA deben mantener el balance entre la eficiencia a corto plazo y la equidad, ya que esta última influye en la viabilidad a largo plazo. Sin embargo, es claro que ni el 'noble salvaje ecológico', que protege su ambiente a capa y espada, ni el campesino demasiado pobre como para causar un daño ecológico significativo, serán los principales vendedores de SA. Ninguno de los dos significa una seria amenaza; entonces, pagarles genera una adicionalidad cero que no hace ninguna diferencia. ¿Es esto injusto? Quizás no, pues ninguno de los dos tiene costos de oportunidad de conservación provocados por el desarrollo no alcanzado. El vendedor ideal de SA no es francamente enemigo del medio ambiente, pero potencialmente podría serlo.
Por otra parte, las amenazas actuales no son el único indicador relevante -y con frecuencia las amenazas se revelan abiertamente cuando ya es muy tarde. El PSA a grupos meta y en áreas donde se espera que la amenaza vaya a golpear (amenaza proyectada) pudiera ser un seguro efectivo contra la degradación futura. CIFOR ha adoptado esta lógica en el intento de desarrollar un esquema de concesiones comunitarias para la conservación en el poblado de Setulang, Kalimantán este, Indonesia (Wunder et al. 2004). La mayoría de los poblados vecinos han vendido sus bosques a empresas madereras, pero Setulang ha preservado cinco mil hectáreas de bosque primario de bajura con el objetivo de proteger las fuentes de agua. Sin embargo, las ofertas de las empresas madereras aumentan y el consenso interno por la conservación está en peligro. En esta situación, un pago externo a los pobladores locales por no vender sus derechos de extracción de madera podría ayudar a que se mantenga el consenso en el poblado. También podría ayudarlos a proteger de manera más eficiente el bosque contra la amenaza externa que significan las empresas madereras. El PSA probablemente tiene un alto potencial para lograr beneficios reales y adicionales de conservación en situaciones donde las decisiones están 'en el filo de la navaja', especialmente cuando se trata de un esquema de uso restringido donde el SA amenaza perderse de manera irreversible (p.e. la biodiversidad). Una vez que se pierde el balance y la comunidad vende sus derechos es obviamente muy tarde para que el PSA tenga algún impacto.

\section{6. ¿A quién pagar?}

En esta sección se analizarán tres aspectos relacionados con la selección de posibles receptores del PSA: la cadena de valor agregado, la inseguridad en la tenencia de la tierra y el uso ilegal del recurso. El primer asunto tiene que ver con la distribución vertical del costo de oportunidad. Veamos el caso de Setulang (Wunder et al. 2004). Para que un PSA por biodiversidad sea políticamente aceptable es necesario compensar a una masa crítica de decisores que de otra manera se beneficiarían con la actividad que amenaza a la biodiversidad (la tala en este caso). La Figura 4 muestra la distribución aproximada de los beneficios generados con la extracción de madera, combinados con el flujo financiero y de materia prima. La madera se extrae del bosque estatal (de iure), cuyos derechos de uso son reclamados por diferentes comunidades locales con derechos tradicionales sobre la tierra (adat) generalmente reconocidos por el estado indonesio post-Suharto.

Sin embargo, los derechos reclamados por las comunidades se traslapan y su poder de negociación varía, lo que genera divergencias en su parte de las ganancias totales obtenidas con la 


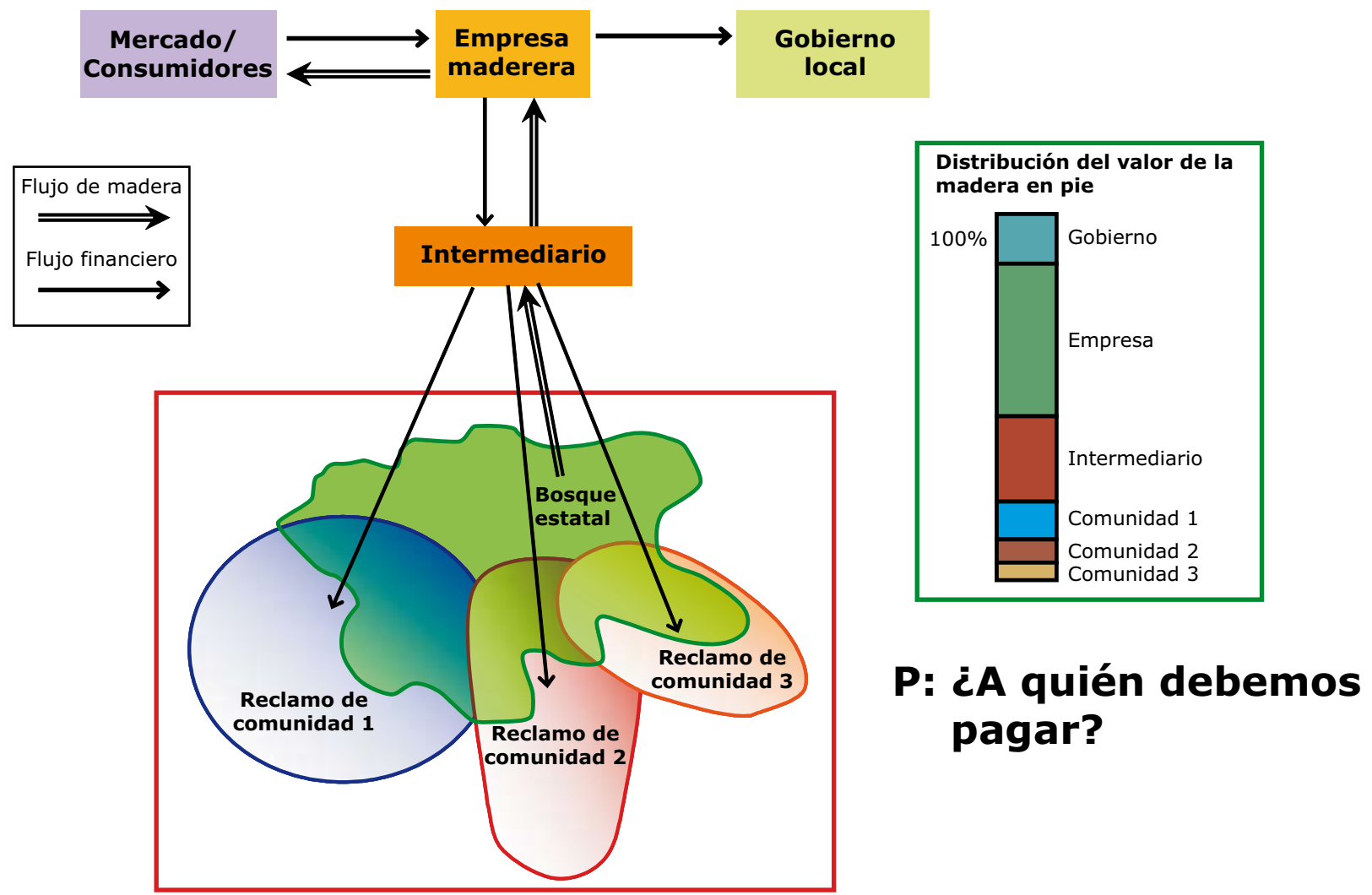

Figura 4. Compra de derechos de aprovechamiento para favorecer la conservación en Indonesia

CIFOR brinda apoyo al poblado de Setulang, Kalimantán Este, Indonesia, en la formulación de un esquema de PSA que evite la tala del bosque de bajura que pertenece a la comunidad, y en la búsqueda de apoyo financiero para preservar el bosque (Foto: Yani Saloh).

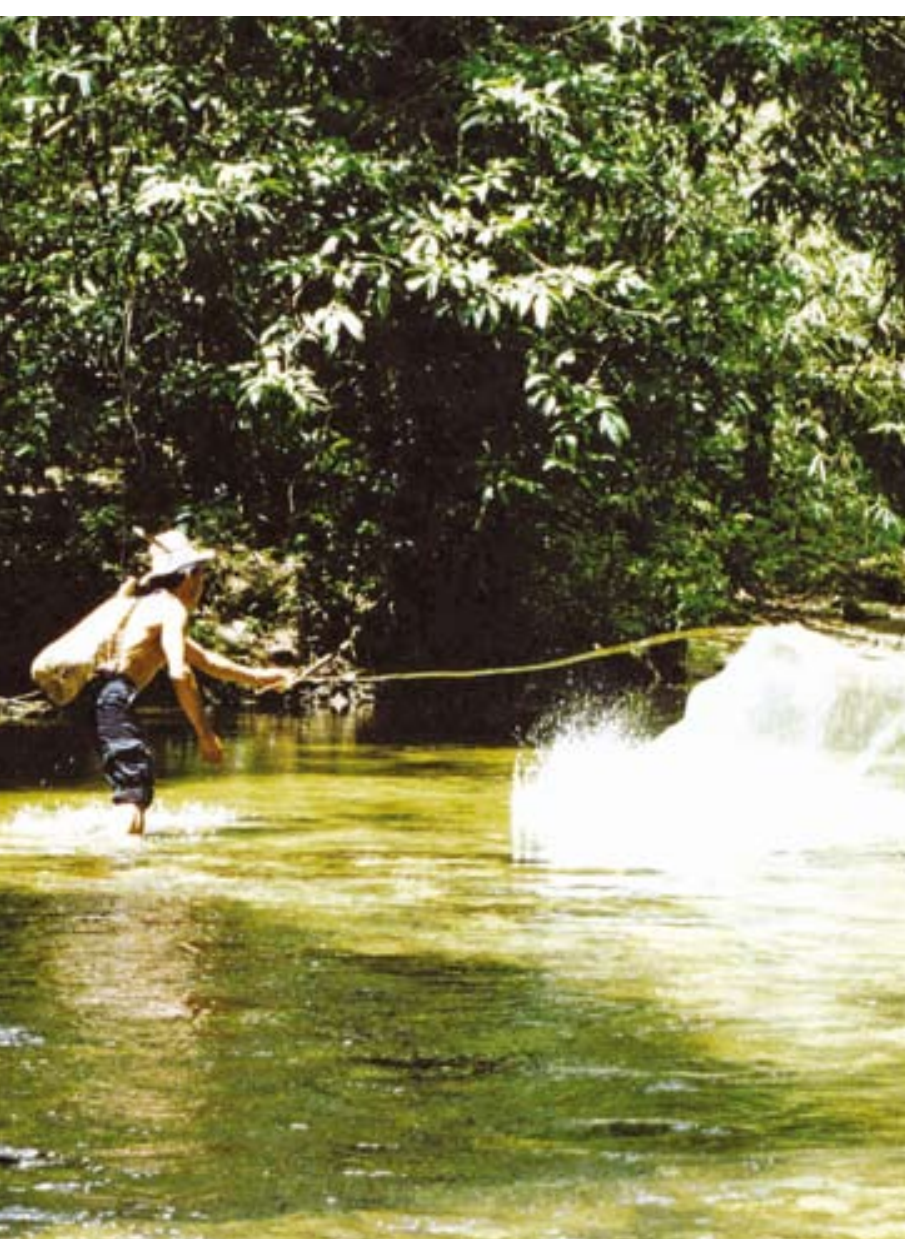

madera (barra de la derecha). Otros agentes, como intermediarios (tarifas), empresas madereras (valor de venta), gobierno local (impuestos, sobornos) y probablemente consumidores de la madera (excedente del consumidor), se llevan la parte del león de las ganancias netas y, por lo tanto, son quienes más perderían si los bosques se conservaran. ¿Debería compensarse a todos estos actores con un esquema de PSA?

Desde el punto de vista de la eficiencia, se debería compensar a bastantes actores (no necesariamente a todos) para formar una alianza de conservación resiliente; habría que escoger entre aquellos que tienen reclamos convincentes para un sitio dado. Generalmente, los consumidores, intermediarios y empresas madereras no necesitan recibir compensación pues sus intereses son 'móviles'. A menos que compren, alquilen $u$ ocupen por la fuerza un área, no pueden presentar reclamos para un sitio específico. Por otra parte, las comunidades que actúan como guardianas locales del bosque tienen un interés particular y sí deben ser compensadas. No obstante, el esquema de PSA no tiene fundamento si la comunidad es demasiado débil como para proteger sus bosques. El gobierno local, fortalecido recientemente por la descentralización, puede funcionar como catalítico y, entonces, merecer compensación, aunque hay pros y contras que debemos evaluar.

Para que un sistema de PSA sea justo, se debiera compensar a todos los que pierden, 
pero en este caso específico la compensación en todos los niveles sería prohibitivamente cara. Nótese que comprar conservación por un precio relativamente bajo, definido solamente por los costos de oportunidad de los pobladores locales podría, eventualmente, generar pérdidas al ingreso nacional pues los actores externos dejarían de percibir grandes rentas por madera (Sección 8). A quién exactamente debemos pagar es un asunto de negociación, viabilidad política (que incluye la idea de equidad), legalidad (en cuanto a la tenencia de la tierra, especialmente) y posiblemente también de ética, pues algunos actores pudieran perder ingresos ilegales, sobornos y ganancias inicuas.

Segundo, muchos propietarios de la tierra en los trópicos no tienen títulos formales de propiedad, especialmente en las áreas de frontera agrícola. ¿Pueden (y debieran) esos usuarios recibir el PSA? La principal preocupación de los compradores privados de SA no debiera ser la propiedad estatal de la tierra, sino la capacidad de facto de uso y control de la tierra y los recursos. Los propietarios informales, cuyos reclamos por la tierra son ampliamente reconocidos y respetados, pueden muy bien ser proveedores eficientes de SA pues ellos pueden controlar el acceso al bosque. Alguien con derechos de propiedad inseguros $y$ débiles no puede ejercer esa función $y$, en consecuencia, agentes externos llegan a ocupar la tierra y aprovechar sus recursos. Al desagregar el complejo concepto de 'derechos de propiedad', la idea del 'derecho a excluir' es particularmente decisiva para la eficiencia de quienes ofrecen los SA. Entre más abierto sea el acceso, menos adecuado el escenario para PSA.

Tercero, aparte de los problemas de uso de la tierra, ¿importa el estatus legal de los usuarios del recurso en la selección de quienes se pueden favorecer con el PSA? Muchas condiciones legales sobre el uso de la tierra son débiles (p.e. los bosques de protección declarados pero que no reciben ningún respaldo) y algunos productos del bosque (como animales silvestres, madera, carbón) en gran medida son cosechados de manera ilegal. ¿Debiera otorgarse un PSA a estos usuarios para evitar el aprovechamiento ilegal? Si así fuera, ¿se estaría alentando a los actores legales a dar el paso hacia el terreno ilegal para calificar para el PSA -o al menos se les alentaría a protestar contra un sistema injusto? ¿Se convertiría el PSA, eventualmente, en un sistema de protección al uso ilegal (Vogel 2002)? De hecho, ya están puestos los fundamentos teóricos para el chantaje ambiental (Mohr 1990), y los incentivos perversos se han convertido en una preocupación real para algunos esquemas de PSA (Pagiola et al. 2004).

De nuevo, no hay una respuesta única para todos los problemas, por lo que se recomienda un enfoque pragmático. En muchos casos, un enfoque como el del "palo y la zanahoria" es conveniente; es decir, complementar las leyes de débil cumplimiento con compensaciones de PSA que cubran parcialmente los costos de oportunidad que el cumplimiento implique -especialmente cuando la declaración de protección viene 'desde arriba' y no se respetan los reclamos locales por tierra. Aun en el bien establecido sistema de PSA de Costa Rica, los campesinos reciben, inter alia, pagos por no deforestar, a pesar de que la deforestación es ilegal en el país.

Sin embargo, puesto que el PSA presupone la libre escogencia del uso de la tierra (sección 2), normalmente no es una herramienta adecuada para fortalecer las áreas protegidas existentes, aunque puede haber excepciones. En la medida en que las áreas protegidas han sido relativamente eficientes en detener la deforestación (Bruner et al. 2001), no se debiera pagar a los ocupantes ilegales para evitar que se establezcan en parques nacionales -a menos que se trate de un 'parque en el papel', sin posibilidades reales de mando y control. Si se paga a los ocupantes ilegales, nos podría 'salir el tiro por la culata' y, más bien, atraer a nuevos ilegales que buscan su parte en la repartición. En última instancia, la decisión de ofrecer zanahorias depende de una valoración realista de qué tan lejos podemos llegar con solamente el palo.

La implementación de un sistema de PSA debe pasar por un análisis de eficiencia de los enfoques existentes y de las motivaciones para la provisión de SA, y de cómo un esquema de PSA afectaría a los proveedores de tales servicios. ¿Mejorarán con el pago los esfuerzos de quienes lo reciben? Al menos parte de la literatura en psicología afirma que los premios extrínsecos pueden minar las motivaciones intrínsecas (Deci et al. 1999), como el interés y orgullo de una comunidad por la conservación de sus bosques. Los premios monetarios también pueden debilitar los mercados sociales ya existentes (Sección 2), tales como lazos sociales y convenios de reciprocidad. Aparentemente, esto es especialmente peligroso en la medida en que los pagos siguen siendo pequeños (Heyman y Ariely 2004). Peor aun, el esfuerzo en conservación por un PSA de poca monta pudiera ser menor que sin ningún pago. Hay que poner atención a esto, pues en la mayoría de los casos los montos pagados por servicios ambientales realmente han sido bajos.

\section{7. ¿Cómo pagar?}

Las formas de pago también tienen que ver con la eficiencia del PSA. Un comprador cínico se interesa poco por la forma de pago; lo único que le importa es que el proveedor firme el contrato. Pero, eventualmente, la sostenibilidad del contrato va a depender del efecto imprevisto de los pagos en el ingreso familiar, cambios en los 
hábitos de consumo y demandas por tierra y mano de obra. Estos cambios pudieran también tener efectos secundarios en la conservación, más allá de lo estipulado en el contrato. Es aconsejable, entonces, pensar con anticipación en (y aun experimentar con) diferentes formas de pago (en efectivo vs. no efectivo) y en la periodicidad de los pagos.

Los economistas por lo general piensan que los pagos en efectivo son la forma más flexible -y por lo tanto, preferible. El efectivo es más apropiado cuando los proveedores del SA dejan de percibir un ingreso en efectivo para cumplir con el contrato de PSA; por ejemplo, reducir la expansión planeada de sus cultivos para la venta con el fin de conservar el bosque que protege las nacientes de agua. De hecho, en esta situación los proveedores de SA difícilmente van a aceptar otros beneficios que no sean el dinero en efectivo, pues esto es precisamente lo que están perdiendo en aras de la conservación.

Muchos profesionales del desarrollo no están muy convencidos de transferir dinero en efectivo a las comunidades rurales pues dudan de con ello se mejore el bienestar a largo plazo. El contar con efectivo puede hacer que la gente se dedique a gastar en bienes innecesarios (alcohol, artículos de lujo, etc.) y se generen problemas sociales. Otros, por su parte, opinan que la transferencia regular de dinero en efectivo es más efectiva para aliviar la pobreza que las contribuciones en especie o los proyectos de desarrollo. Por ejemplo, en dos programas recientes de transferencia de fondos a víctimas de inundaciones y a soldados desmovilizados en Mozambique se ha comprobado un buen uso del dinero, los costos administrativos han sido muy bajos (5-10\%) y el impacto en el alivio de la pobreza impresionante (Hanlon 2004).

Un ejemplo de campo sobre PSA ilustra aspectos entre estos dos extremos. El Cuadro 1 resume diferentes actitudes recavadas mediante entrevistas en Santa Rosa (Bolivia) en cuanto a los pros y contras de recibir colmenas (la forma de pago en especie) o dinero en efectivo (opción hipotética), como pago por el servicio ambiental ofrecido (Robertson y Wunder 2005). Los beneficiarios originalmente negociaron una cierta cantidad de colmenas y asistencia técnica sobre apicultura. Como lo explicaba uno de los campesinos participantes en el programa: "Si recibo dinero en efectivo, sé que lo voy a gastar de una vez; en cambio, con esta forma de pago voy a crear algo que va a durar". Esta afirmación refleja no sólo la resistencia a recibir dinero en efectivo, sino también las expectativas de los beneficiarios de obtener intervenciones 'integradas' (a menudo paternalistas): esperan que la ONG mediadora les ofrezca un paquete completo y 'pre-cocido' de beneficios. Esta, bien puede ser una actitud racional si las capacidades locales para el ahorro, la inversión y la capacidad empresarial son limitadas. Otros beneficiarios afirmaron que la miel es un producto útil para la subsistencia, y que recibir colmenas causa menos inquietud por la expropiación de la tierra que el dinero en efectivo, independientemente de si tales temores son justificados o no.

Para la ONG, la necesidad de garantizar un hábitat a las abejas significó un incentivo local adicional para conservar el bosque. Además, las colmenas tienen un mayor 'efecto demostrativo' que algunos pequeños pagos en efectivo. La

Cuadro 1. Ventajas y desventajas percibidas en dos sistemas de PSA en Santa Rosa (Santa Cruz, Bolivia), Fundación Natura. Comparación de pagos en efectivo y en especie.

$\begin{array}{ll}\begin{array}{l}\text { Ventajas de colmenas / Desventajas del } \\ \text { efectivo }\end{array} & \begin{array}{l}\text { Ventajas del pago en efectivo / Desventajas } \\ \text { del pago en especie }\end{array}\end{array}$

\section{- Algunos beneficiarios rechazan el dinero - se gasta rápidamente y no deja beneficios a largo plazo}

El pago en efectivo 'huele' a perder derechos de propiedad - no importa si este temor es racional o no

- La miel es un producto útil para la subsistencia

La apicultura recibe un incentivo por la protección del bosque como hábitat de las abejas

Efectos demostrativos de las abejas y sabor de la miel da a quienes implementan el PSA mayor influencia que la simple transferencia de dinero
Beneficiarios poco habilidosos o poco interesados en la apicultura pierden sus beneficios

Para la venta, las colmenas son bienes inflexibles, en comparación con animales o equipo

En comparación con el efectivo, las colmenas son bienes difíciles de subdividir

Costos extras de capacitación para la implementación de ONG

Costos extras para los beneficiarios - la apicultura exige mano de obra 
ciencia psicológica asegura que, para estimular el esfuerzo, los pagos en especie y de poco valor pueden ser más efectivos que los pagos en efectivo de poco valor, pues los beneficiarios perciben las transferencias en especie como más compatibles con el intercambio recíproco y el mercado social (Heyman y Ariely 2004).

Sin embargo, los beneficiarios que preferirían recibir dinero en efectivo alegaban que las colmenas son bienes inflexibles que requieren de mano de obra y de cierta capacitación, lo que implica que aquellos no muy dedicados a sus colmenas lograrían una rentabilidad muy baja o nula. La ONG que ofrece capacitación en apicultura también significa un costo adicional. Algunos beneficiarios esperaban vender las nuevas colmenas a aquellos que se especializaran en abejas -creándose así un 'mercado secundario interno' de intercambio de colmenas por dinero en efectivo. Otros prefieren los pagos en especie, como alambre de púas para cercar sus propiedades y hacer valer su derecho de propiedad. Al menos que signifique un costo administrativo muy alto, sería preferible tener una variedad de formas de pago, aun en el mismo sitio.

Este pequeño ejemplo demuestra que es aconsejable investigar primero las formas de pago que los pobladores locales prefieren. Las preferencias pueden variar entre poblados, familias y aun individuos de la misma familia, por lo que es deseable usar un enfoque 'a gusto del cliente'. Los aspectos de género entre los beneficiarios también debieran monitorearse, $y$ en algunos casos es posible que sea mejor un contrato colectivo y no individual (Sección 8). En cuanto a periodicidad, es deseable emular a otros flujos de ingresos regulares con pagos pequeños y frecuentes -aun si el monitoreo para controlar el cumplimiento se hace una vez al año. Esto es particularmente importante cuando se usan pagos en efectivo y la tentación de gastarlo rápidamente es mucha. Pero hay que determinar caso por caso qué es lo más apropiado para aumentar el bienestar. Algunos beneficiarios van a preferir las opciones de pago en especie, pero las comunidades con poco circulante muchas veces van a preferir el efectivo. Quienes implementan el PSA deben superar los prejuicios paternalistas en cuanto a que los pobladores locales por lo general son incapaces de administrar el dinero que les llega.

Finalmente, se ha sugerido que los sistemas de PSA debieran incluir también la transferencia contingente de infraestructura, como la construcción de escuelas o caminos, o de derechos sobre los recursos a los pobladores locales, como la tenencia formal de la tierra (Rosa et al. 2003, van Noordwijk et al. 2004). El problema aquí es que los beneficios directos grandes o irreversibles son incentivos dudosos para mantener el abastecimiento continuo de los servicios contratados. ¿Cómo hacer para sancionar el no cumplimiento -un aspecto primordial de cualquier acuerdo contingente? Posiblemente el cumplimiento se pudiera amarrar al costo de mantenimiento de la infraestructura; p.e. el costo de mantener la escuela o el camino abiertos. Pero aun así, el mantenimiento del camino puede ser asumido por una empresa maderera o un empresario agrícola que promueven un uso de la tierra contrario a lo que esperaban los compradores del SA. Por ello, estos tipos de incentivos por lo general son más apropiados para PICD que para esquemas de PSA. Para una organización conservacionista es muy mala propaganda llegar y destruir la escuela o el camino, o retirarle a la gente sus recién adquiridos derechos sobre la tierra, sólo porque no cumplieron con su parte del trato.

\section{8. ¿El PSA a favor de los}

En un momento en que la ayuda internacional al desarrollo se centra cada vez más en el alivio de la pobreza, no es sorprendente que se evalúe el potencial de enfoques novedosos como el PSA para el logro de ese objetivo. Se espera que los proveedores pobres de SA (p.e. agricultores ubicados en las partes altas de cuencas remotas) logren mejorar su ingreso mediante un pago otorgado por los compradores de SA que poseen mayor riqueza (p.e. usuarios urbanos del agua); de hecho, a algunos donantes les interesa el PSA sólo por sus efectos esperados en beneficio de los pobres.

Conceptualmente, es conveniente prestar atención a tres preguntas relacionadas con la pobreza (Grieg-Gran et al. 2005):

1. Participación: ¿Qué acceso pudieran tener y por cuál parte del mercado pudieran competir los proveedores potenciales pobres de SA, bajo un esquema de PSA?

2. Efectos en los vendedores de SA: ¿Cómo influye la participación en el PSA en las condiciones de vida de los proveedores pobres que logran tener acceso al sistema?

3. Efectos en los no vendedores: ¿cómo afecta el PSA a la gente pobres que no vende servicios (agricultores que no participan, usuarios pobres de SA, consumidores de productos, trabajadores sin tierra, etc.).

\subsection{Acceso a la participación en el PSA}

Los campesinos pobres que buscan convertirse en vendedores de servicios ambientales enfrentan reglas explícitas de acceso al PSA y restricciones estructurales subyacentes. Las reglas explícitas de acceso al PSA pueden favorecer o no a los pequeños propietarios. En el análisis de seis 
proyectos de carbono y dos de manejo de cuencas, Grieg-Gran et al. (2005) descubrieron una mezcla de condiciones. Algunas reglas discriminaban a los pequeños propietarios, como los requisitos de tenencia formal de la tierra y la exclusión de los sistemas silvopastoriles y agroforestales; otras -como el tamaño máximo de la finca y el enfoque en regiones subdesarrolladas- eran favorables a los pobres rurales.

Hay dos restricciones estructurales subyacentes principales. "Los más pobres entre los pobres" no poseen ni controlan la tierra, lo cual les excluye como proveedores potenciales de SA -al menos de los esquemas de PSA por área. Entonces, por naturaleza el PSA se dirige a campesinos 'moderadamente pobres'. Aun aquellos pobres que controlan una parcela de terreno a menudo no tienen derechos legales sobre ella. Como se dijo en la Sección 6, un esquema de PSA que busque aliviar la pobreza, en la mayoría de los casos, podría solucionar el problema de la tenencia informal, pero si no hay un control efectivo del uso de la tierra, sería mucho más difícil impulsarlo mediante la intervención externa.

Una segunda restricción estructural son los altos costos de transacción que implica tratar con muchos pequeños propietarios, o terrenos de propiedad colectiva que pertenecen a comunidades con conflictos internos, en comparación con unos pocos grandes propietarios (Smith y Scherr 2002). Esta situación se exacerba si hay economías de escala en la provisión de servicios; por ejemplo, cuando el secuestro de carbono pasa por un proceso de certificación con costos fijos elevados. De nuevo, un diseño creativo para 'empaquetar' pequeños propietarios, como lo hace el esquema de PSA en Costa Rica, puede ayudar a solventar esta restricción. 'Proyectos burbuja' de secuestro de carbono son un caso similar de ahorro de costos mediante la participación de regiones o cantones, en vez de propietarios individuales (Smith y Scherr: 34-5). Obviamente, esto hará que al menos parte de los costos de transacción pasen del comprador a aquellas instituciones vendedoras encargadas de asegurar que el compromiso colectivo se transforme en niveles aceptables de acatamiento individual. Todas estas medidas probablemente reduzcan los costos de transacción, pero difícilmente eliminarán la restricción estructural, propiamente dicha. Trabajar con tres proveedores de SA casi siempre será más fácil que trabajar con trescientos.

Naturalmente, estas 'desventajas comparativas' deben sopesarse contra las ventajas correspondientes. En particular, los pequeños propietarios pueden tener costos de oportunidad significativamente más bajos de mano de obra y posiblemente de la tierra (marginal) (Costa y Zeller 2003). En la medida en que las tasas de PSA por unidad de terreno son bajas, para los

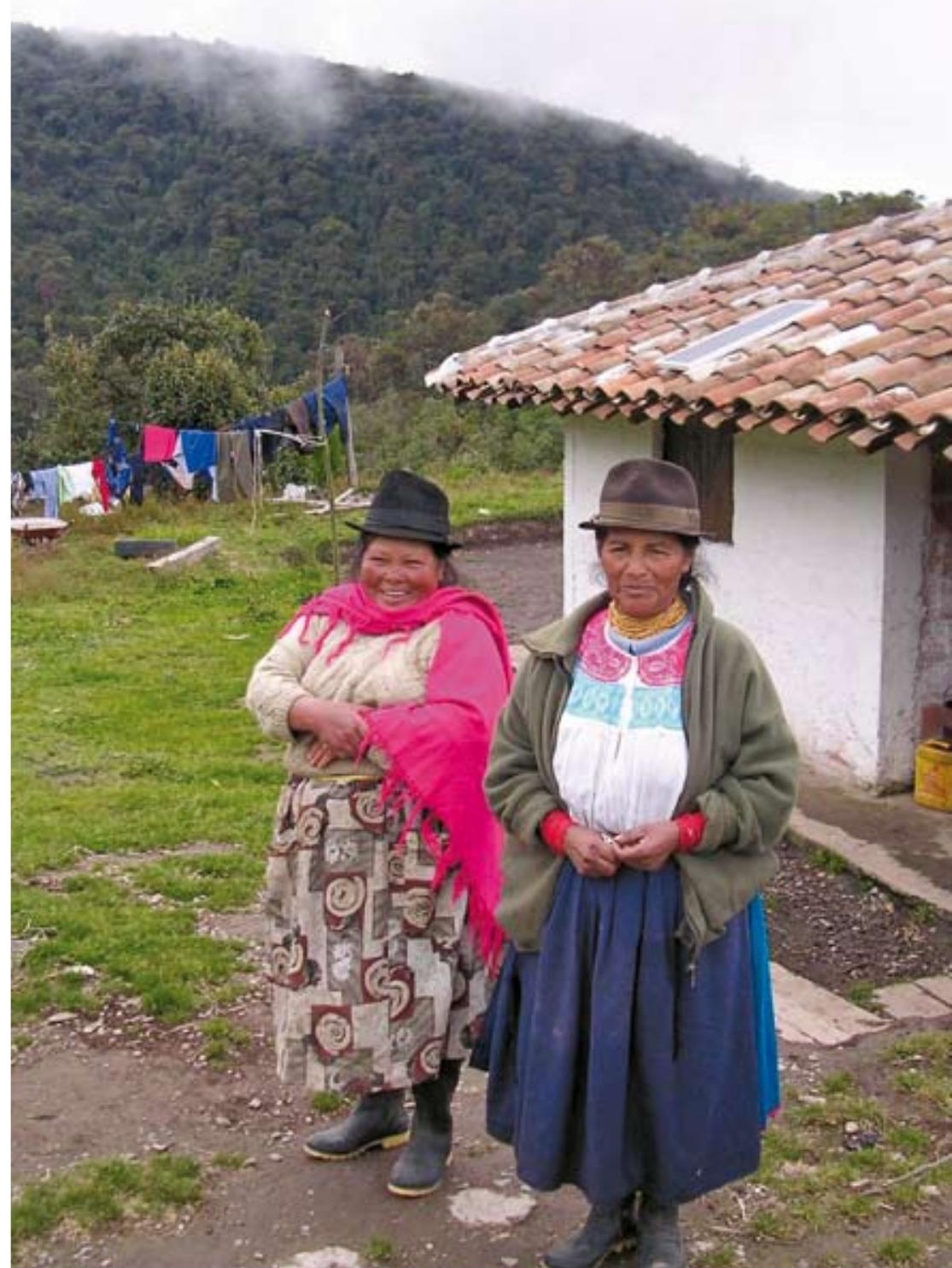

Dos beneficiarias de PSA en Nueva América, Pimampiro, Norte de Ecuador. Los usuarios urbanos del agua pagan por la protección de las nacientes (Foto: Sven Wunder).

actores ricos -con mejor acceso al capital y a la tecnología y, por lo tanto, con mayores costos de oportunidad- no será rentable competir con los proveedores pobres. Estas ventajas potenciales de los proveedores pobres pueden (o no) compensar sus altos costos de transacción. A menudo es más simple lograr altas tasas de participación de los pequeños propietarios en servicios espacialmente muy restringidos (p.e. la protección de una cuenca) donde los compradores tienen que trabajar con quienquiera que esté ocupando el espacio; sin embargo, el dilema de los costos de transacción se hace más evidente en servicios homogéneos con un alto grado de movilidad espacial y competencia (en especial el secuestro de carbono). 


\subsection{Efecto en los vendedores de SA} Una vez que los proveedores pobres de servicios han logrado ingresar al mercado de servicios ambientales, ¿cómo les irá? Como se explicó en la Sección 2, los contratos de PSA son acuerdos voluntarios por lo que a los proveedores individuales de servicios les irá peor sólo si se les engaña, se les obliga a participar, se les causa un impacto inesperado en sus condiciones de vida (p.e. debido a que se subestimaron los costos de oportunidad) o se afecta la economía local de forma indirecta (p.e. cambios en el mercado laboral o de la tierra).

De estas posibilidades, la última es quizás la más probable (ver análisis más adelante), aunque siempre existe la posibilidad de salirse del esquema de PSA o de renegociar opciones. Siempre podrían potencialmente darse casos en que los vendedores de servicios se vean atrapados por el PSA en condiciones de vida negativas; por ejemplo, cuando se firman acuerdos de largo plazo sobre el uso del suelo basados en un acceso desigual a la información. Sin embargo, hasta ahora no se han publicado ejemplos reales convincentes sobre las trampas del PSA. El PSA ofrece una fuente adicional de ingresos, por lo general en áreas con poca diversificación donde el efectivo es escaso; además, el flujo en efectivo es potencialmente más estable que otras fuentes alternativas, como los cultivos para la venta con precios muy fluctuantes. Al menos este es el caso si los compradores cumplen con sus obligaciones para financiar el programa de PSA y si este es bien administrado (Pagiola et al. 2005).

Aun si mejoran las condiciones de vida de los proveedores pobres de SA, siempre quedan preguntas en cuanto a 'en qué medida' y 'de qué forma' ganarán con la participación. Como en cualquier transacción comercial, siempre hay un conflicto inherente en cuanto al precio entre los compradores de SA que quieren maximizar el superávit del consumidor (la mayor conservación por cada peso invertido), y los proveedores de SA que quieren aumentar el superávit del productor (pagos netos de los costos de oportunidad). Por lo general (aunque no siempre), los compradores están en una posición negociadora más ventajosa pues son menos en número, están mejor informados y son quienes promueven la iniciativa. Por ejemplo, se han hecho más estudios de costos de oportunidad que de voluntad de pago; en consecuencia, los compradores saben más sobre los vendedores que al contrario. Si se mejora la organización y los niveles de información entre los proveedores de SA se podría acrecentar su posición negociadora.

Al margen de posibles asimetrías de poder, el PSA viene a significar una parte importante de los ingresos familiares de los participantes -al menos es lo que podemos decir con los estudios preliminares disponibles. En Costa Rica, los pagos por servicios ambientales representaban más del $10 \%$ del ingreso familiar para más de un cuarto de los participantes (E.Ortiz, citado por Pagiola et al. 2005); el esquema de PSA del Virilla aportaba el $16 \%$ de los ingresos en efectivo, aunque tres cuartos de los beneficiarios recibían ingresos por más de US\$820 mensuales, por lo que no se puede decir que fueran pobres (Miranda et al. 2003). Sin embargo, en zonas de pobreza real la situación puede ser muy diferente. En la península de Osa, Costa Rica, una pequeña encuesta determinó que para los beneficiarios del PSA que estaban bajo la línea de pobreza, a la mitad de ellos el pago les permitió superar esa condición y en el $44 \%$ de los casos se convirtió en la principal fuente de ingresos en efectivo (Muñoz 2004). En Pimampiro (Ecuador), los pagos por la protección de cuencas a colonos pobres de la cuenca alta compensaron el $30 \%$ de los gastos del hogar en alimento, medicina y escuela (Echavarría et al. 2004). Los proyectos de carbono de PROFAFOR en sitios de bajos ingresos en Ecuador y el proyecto Huetar Norte en una región deprimida de Costa Rica crearon empleo inmediato y una importante base de ingresos a futuro (Miranda et al. 2004, Albán y Argüello 2004, Milne 2000). Obviamente, los ingresos reportados son brutos, pues no conocemos el tamaño del costo de oportunidad (ingresos no percibidos debido a restricciones en el uso de la tierra inducidas por el PSA), el cual podría ir desde cero hasta el pago total recibido por el PSA. Sin embargo, al menos para las regiones deprimidas, el tamaño relativo del ingreso percibido con el PSA pareciera ser significativo.

Algunas veces los beneficiarios reciben algo más que dinero por su participación: los beneficios no monetarios adicionales pueden ser tan importantes como el dinero mismo (Rosa et al. 2003). Es necesario rescatar tres elementos. Primero, los participantes perciben que los contratos de PSA pueden mejorar la seguridad sobre la tenencia de la tierra ante los vecinos o precaristas, ya que exige el mapeo y demarcación de la tierra y permite demostrar que se está realizando una actividad que genera ingresos. Rosa et al. (2003) lo confirmó en varios estudios de casos de América Latina, y también lo confirmamos nosotros con nuestro estudio en Santa Rosa, Bolivia, donde los terrenos boscosos son fuertemente amenazados por los emigrantes sin tierra procedentes de las zonas altas. Segundo, los participantes en esquemas de PSA tratan de mejorar la organización interna para aumentar su 'capital social'; por ejemplo, cuando se requiere negociar o interactuar con los compradores del servicio (Rosa et al. 2003, Grieg-Gran et al. 2005). Algunos beneficios del PSA se obtienen del 'aprender haciendo'; otros se obtienen desde el principio (p.e. capacitación formal). Este efecto en el capital social por lo general beneficia a los pobladores locales en sus relaciones comerciales con el mundo exterior. 


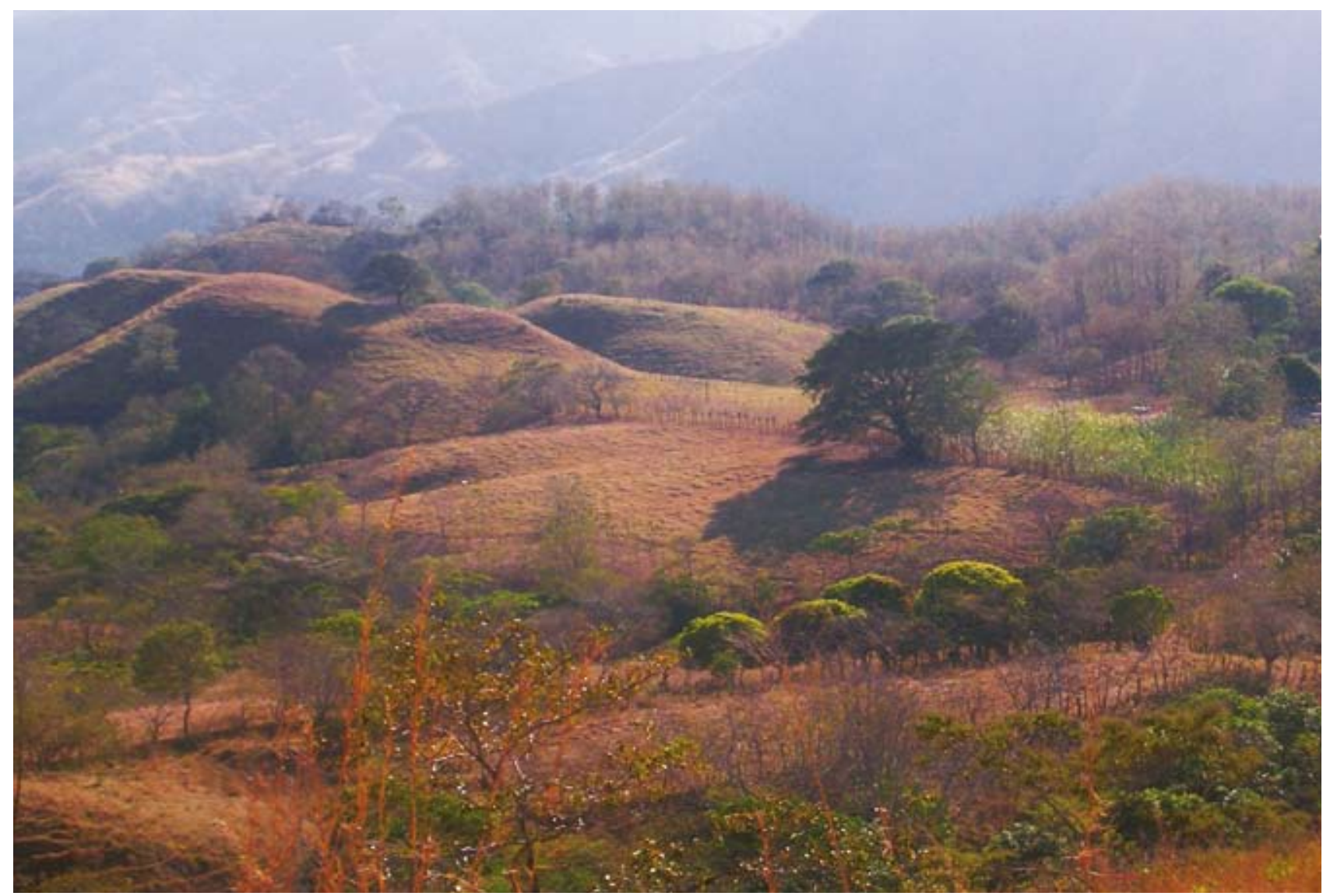

Los pagos por servicios ambientales son más efectivos en tierras marginales, donde un pago modesto puede inclinar la balanza a favor de la conservación. Bosque seco en la provincia de Guanacaste, Costa Rica, donde se abandonan los pastizales para incluirlos en el programa de PSA (Foto: Sven Wunder).

También pueden darse algunos efectos sociales negativos (p.e. tensiones entre participantes y no participantes). Finalmente, el programa de PSA funciona como un sitio estratégico de propaganda y aumenta la visibilidad del poblado o comunidad ante los donantes y entidades públicas. Por ejemplo, en Bolivia encontramos que para algunos poblados involucrados en iniciativas de ecoturismo o belleza escénica era más fácil atraer donantes para construir una clínica, o lograr el reconocimiento municipal de sus reclamos por tierra.

\subsection{Efecto en los pobres que no venden SA}

¿Qué sucede con la gente pobre que no participa del PSA pero que siempre se ve afectada por él? Esto es mucho más difícil de determinar, pues este grupo residual es bastante heterogéneo y porque los impactos son dominados por complejos efectos secundarios que ocurren en los factores de producción (tierra, mano de obra) y en los mercados de productos (cultivos agrícolas, productos forestales, etc.). Analicemos tres grupos potenciales de pobreza: usuarios del servicio, campesinos sin tierra ubicados en el sitio y actores externos que participan de la cadena de valor agregado.

Primero, no todos los usuarios de SA son adinerados. Los campesinos pobres del trópico probablemente sufrirán más con el calentamiento global porque no tienen los medios para adaptar sus sistemas agrícolas $y$, por consiguiente, se verán beneficiados con los esfuerzos de mitigación (IPCC 2001). Los usuarios urbanos del agua en barrios marginales no pagan por el servicio de agua potable porque sus conexiones no tienen medidor del consumo y, entonces, aprovechan gratuitamente cualquier mejora en la calidad o disponibilidad del agua que se logre mediante el PSA. Así, los consumidores que no pagan disfrutan de un mejor servicio, en tanto que sus vecinos de barrios cercanos que sí pagan por el agua podrían sufrir un empeoramiento de sus condiciones a medida que las tarifas suben para financiar el PSA.

Segundo, en muchos casos los más pobres y desposeídos se enrolan en (o son contratados por) algunas de las actividades que más amenazan a los SA, tales como trabajadores de empresas madereras, fabricantes de carbón y leña, 
extractores de productos forestales no maderables (PFNM), o mano de obra contratada para talar y cultivar. En la medida en que los esquemas de PSA restringen los usos del suelo (Sección 2); es decir, que limitan la extracción planificada de productos del bosque o el uso agrícola, los grupos involucrados en estas actividades llevan las de perder en cuanto a fuentes de empleo o de ingreso informal. Por ejemplo, las restricciones establecidas por el PSA afectaron a los pastores y recolectores de PFNM en India (Kerr 2002). En Santa Rosa, los campesinos pobres involucrados con el PSA por conservación quieren protegerse de inmigrantes sin tierra que vienen con la clara intención de ocupar terrenos 'ociosos'. Esto demuestra que hay subgrupos de pobres con intereses antagónicos en cuanto a la implementación de PSA. Por contraste, si la provisión de SA permite un realce productivo, como el establecimiento de plantaciones forestales en suelos degradados con pocas alternativas de producción, esto pudiera provocar una expansión neta de trabajo rural y beneficios para la mano de obra no calificada que ayudarían a aliviar la pobreza.

Si bien los efectos pueden ir en los dos sentidos, en algunos casos su tamaño puede ser significativo. Por ejemplo, el despido de taladores y aserradores fue la principal razón para implementar un PICD compensatorio por parte del Proyecto Noel Kempff Mercado en Bolivia (Asquith et al. 2002). Si el PSA es localmente lucrativo, se pudiera dar una competencia entre quienes poseen terrenos elegibles, en detrimento del acceso a la tierra para los actores más débiles (Rosa et al. 2003).

Finalmente, los cambios rurales inducidos por el PSA pudieran provocar efectos fuera del área. Por ejemplo, los consumidores pobres de carbón en las ciudades pudieran enfrentar un alza en el precio del producto si un área de bosque donde se produce mucho carbón se reserva para fines de conservación. Y a la vez, el aumento en los precios podría beneficiar a los productores pobres en otros sitios. Si las rentas económicas que la madera genera van a parar a la capital principalmente, entonces, el restringir el aprovechamiento puede afectar indirectamente a la gente pobre que trabaja -digamos- en el sector urbano de servicios que tales rentas estimula. La restricción en el abastecimiento de materia prima pudiera traer importantes impactos en la cadena de desarrollo -que obviamente deben compararse con los 'efectos multiplicadores' causados por la inyección de recursos financieros del PSA. No existen estudios empíricos sobre estos nexos; la mayoría de la veces uno esperaría que fuesen menores que los efectos en el sitio, pero las rentas de la madera pudieran ser una excepción importante, como se vio en la Sección 6.

\section{Conclusión y perspectivas}

\section{1 ¿Cuándo es el PSA el mejor instrumento para la conservación?}

"Dale un pez a un hombre y tendrá qué comer hoy. Enséñale a pescar y tendrá qué comer toda la vida."

Este popular proverbio refleja bien el atractivo de los PICD y de otros enfoques indirectos: la eliminación de los obstáculos al desarrollo sostenible (pobreza, escasez de capital, tecnología y capacidad humana) 'arreglaría el problema' y haría que la gente se comprometiera -en principio para siempre- con la conservación. Este mensaje sobre la supuesta sinergia entre desarrollo y ambiente, ya claro en el Informe Brundtland y en Río 1992, fue políticamente atractivo pero, desafortunadamente, en el campo de la conservación los defectos de la estrategia de 'enseñar a pescar' son cada vez más evidentes.

Los PICD reciben dos críticas principales. Primera, aunque se le enseñe al hombre a pescar, él todavía tiene tiempo y recursos para sacar madera, cazar y 'botar montaña' -en principio, nada le obliga a cambiar sus costumbres. Segunda, ¿qué se necesita para enseñar al hombre a pescar? Si se requiere un documento de estrategia, dos planes de desarrollo del poblado, tres talleres participativos, cuatro especialistas en investigación - acción, una planta procesadora de pescado y un ejército de consultores y personal de proyecto, saldría mucho más barato darle un pescado al hombre cada día. Esta es precisamente la justificación del PSA -la promesa de mejorar la eficiencia al darle al hombre un pescado como premio directo sólo si conserva.

A pesar de lo atractivo que resulta el PSA por su estilo directo, quedan varios asuntos pendientes. Primero, como comprador de servicios ambientales, usted necesita una fuente sostenible de ingresos para financiar el PSA, muchas veces a perpetuidad. Además, mientras la demanda se mantenga restringida, es poco realista suponer que aumente la oferta de servicios ambientales. Ninguna asociación de desarrollo comunal puede simplemente decidir de forma independiente en una reunión interna el tipo de servicio que van a ofrecer durante el próximo período fiscal. Excepto por los servicios de carbono geográficamente dispersos, todos los demás SA son específicos de un sitio, lo que implica que los compradores o intermediarios son quienes toman la iniciativa de acercarse a los proveedores, porque son concientes de que estos últimos controlan un bien ambiental estratégico y cada vez más escaso. 
Segundo, hay que construir confianza o 'capital social' para el PSA. Al ofrecerle un pescado, el hombre en la montaña puede pensar que, en realidad, usted quiere su tierra, o algún otro negocio sospechoso. Generar confianza y definir las reglas, el monitoreo y recompensas puede ser engorroso y lento, por lo que se requiere de la participación de un intermediario honesto -una ONG, por ejemplo- aun así, el éxito no está garantizado. De hecho, puede ser que las comunidades no acepten un acuerdo quid pro quo cuando están acostumbradas a recibir beneficios gratuitos de múltiples donantes y agencias. Décadas de proyectos de desarrollo rural paternalista hacen surgir expectativas difíciles de romper, aun si ambas partes del acuerdo resultarían beneficiadas.

El PSA también puede tener altos costos de transacción. De hecho, en algunos casos la estrategia de conservación más racional es la compra directa de terrenos, y no un esquema de PSA que compra derechos de uso de la tierra por plazos definidos. En otros escenarios, la mando y control seguirán siendo preferibles a los incentivos económicos. En otros más, los PICD siguen siendo la mejor opción pues el cambio a una forma de producción privada más sostenible y, a la vez, más rentable puede lograrse con intervenciones puntuales -esta es una opción más atractiva para el comprador, quien no tendrá que continuar pagando por siempre. Quizás pronto surgirá una nueva generación de 'PICD contingentes'. Un híbrido entre PSA y PICD permitiría ofrecer pagos puntuales por adopciones tecnológicas, como en el proyecto RISEMP donde los ganaderos reciben pagos condicionados por dos o cuatro años y asistencia técnica para cambiar los pastizales sin árboles a sistemas silvopastoriles (Pagiola et al. 2004). En otras palabras, muchos enfoques diferentes seguirán siendo relevantes en formas nuevas y más directas.

Los profesionales en conservación a menudo sienten una atracción irresistible por los escenarios de amenazas altas que requieren intervenciones urgentes. ¿Es aquí también donde debiera enfocarse el PSA? Ciertamente el PSA tiene sentido donde existe una amenaza actual o proyectada; sin amenaza no hay adicionalidad y, por lo tanto, el PSA no tiene razón de ser. Pero si una amenaza grande significa altos costos de oportunidad, por lo general el PSA no es la mejor respuesta. Con frecuencia no se cuenta con los fondos suficientes; entonces, es más inteligente 'dejar ir' esos escenarios o aplicar otras herramientas. De igual manera, si el uso de la tierra deseado es ya más rentable que el no deseado, normalmente tampoco tiene sentido aplicar un PSA. El PSA logra su mejor desempeño en el rango intermedio de costos de oportunidad, positivos pero numéricamente pequeños: pastizales degradados, cultivos marginales, bosques en zonas de frontera agrícola de lento avance, etc. Al igual que otros incentivos económicos, el PSA logra su mejor desempeño en el margen de ganancia, cuando un pago pequeño a los propietarios de la tierra incline la balanza a favor de un uso deseado de la tierra. En los escenarios con amenazas proyectadas, el PSA podría funcionar como una forma de seguro ambiental.

\section{2 ¿Cómo diseñar un esquema de PSA?}

Si nos decidimos por la implementación de un PSA, ¿cuáles pasos debiéramos seguir para diseñar un esquema aceptable? Aparte unas pocas excepciones (el sistema de PSA de Costa Rica, o algunos proyectos de carbono), la mayoría de las iniciativas de PSA en los trópicos son incipientes, por lo que todavía es prematuro para determinar sus impactos en la conservación y en las condiciones de vida de los beneficiarios. Conceptualmente, es necesario establecer la diferencia entre un 'PSA verdadero' y la gran familia de iniciativas 'parecidas al PSA'. Los primeros son pocos; los últimos muchos, aunque sería deseable convertir algunos de los últimos en PSA verdaderos para probar los principios del PSA, especialmente el condicionamiento. El PSA basado en área vs. producto o en esquemas privados vs. estatales, también plantea algunas diferencias en el diseño. Los esquemas de uso restringido vs. realce productivo tienen diferentes impactos en los niveles de actividad rural.

Para los compradores de SA es esencial contar con una línea base de planificación y posterior valoración de la adicionalidad del PSA; de otra forma, los fondos se van en el pago de cosas que de todas formas habrían ocurrido. Al respecto, es muy útil tener alguna idea sobre los costos de oportunidad de conservación y restauración que deben asumir los proveedores del SA -lo cual a menudo es más útil que la valoración económica completa del flujo de SA. Por varias razones, no es conveniente pagar a cualquiera que ofrezca un servicio ambiental, basándose en un principio políticamente atractivo de justicia (Rosa et al. 2003, van Noordwijk et al. 2004, Gutman 2003). Primero, porque nunca se tendrían los fondos necesarios para pagar 'a todo el mundo'. El caso de Costa Rica, donde las solicitudes exceden los fondos disponibles por un factor de tres, es un ejemplo ilustrativo (Rojas y Aylward 2003).

Segundo, porque ser 'proveedor de SA' con frecuencia sólo significa no ser un vándalo del medio ambiente. El acto de dar derechos generalizados de PSA podría producir incentivos para el chantaje ambiental por parte de cualquier dueño de tierra ambientalmente estratégica -inclusive cuando ella no fuese amenazada. Por ejemplo, los dueños de bosques en Escandinavia podrían amenazar con cortar sus árboles si no se les 
concede el pago por almacenamiento de carbono, - hasta remotas comunidades indígenas podrían amenazar con contaminar deliberadamente el río que abastece de agua a poblados aguas abajo, si no se les paga por conservar la cuenca. Es crucial que el principio subyacente en el PSA de 'la víctima paga' no sea llevado hasta estos extremos absurdos. Por el contrario, los pagos deben ser aplicados estratégicamente en aquellos casos en que la adicionalidad pueda demostrarse claramente. Sólo de esta manera se logrará mantener la voluntad de pago de los usuarios a lo largo del tiempo. Sin embargo, esto también significa que la gente que vive en armonía con la naturaleza, sin ninguna razón aparente para poner en peligro los SA y sin amenazas externas, por lo general no va a calificar como beneficiario del PSA.

Si ni el noble salvaje, ni los amantes de la naturaleza, ni los agricultores que involuntariamente protegen el medio ambiente son el objetivo principal del PSA, entonces ia quién debiera pagarse? Aquellos que tienen costos de oportunidad por conservación, actuales o proyectados, y reclamos aceptables en un sitio específico, son quienes debieran ser pagados. Una empresa maderera califica únicamente si tiene una concesión y la trabaja. Un precarista necesitaría que sus derechos sobre la tierra, si bien informales, sean ampliamente respetados y válidos, con una perspectiva de beneficiarse de su explotación extensificada. Por su parte, los compradores de SA no necesariamente tienen que privarse de negociar con los ocupantes informales en tanto que estos demuestren que tengan la capacidad de controlar efectivamente el acceso de terceros a la tierra. Los compradores también pueden usar 'zanahorias', donde las restricciones legales han resultado inefectivas, a menos que esto conduzca claramente a incentivos perversos. Estas opciones serán superiores en esquemas de PSA privados y localizados, comparado con sistemas estatales en los que la flexibilidad y adicionalidad serán típicamente más bajas.

Las formas de pago deben negociarse por adelantado con los beneficiarios del PSA; hay que escoger entre pago en efectivo, en especie o asistencia técnica -o combinaciones de los mismos. Beneficios irreversibles de facto, como la seguridad sobre la tenencia de la tierra, pudieran eventualmente ser una precondición para el establecimiento del PSA, pero no son incentivos efectivos para la provisión de SA. De igual manera, los esquemas sesgados hacia grandes beneficios directos, en especie o efectivo, no son compatibles con la provisión de servicios continua y a largo plazo, por lo que deben evitarse. La selección de la forma de pago debe tomar en cuenta si los costos de oportunidad son en efectivo o beneficios en especie que se dejaron de recibir. Imitar los flujos de ingresos regulares con pagos pequeños pero frecuentes es muchas veces una opción racional en términos socioeconómicos.

¿Se convertirá el PSA en un motor para el alivio de la pobreza? Trabajos publicados con resultados comparativos (Landell-Mills y Porras 2002, Rosa et al. 2003, Pagiola et al. 2005, Grieg-Gran et al. 2005) concluyen en que:

- es probable obtener efectos netos positivos para los vendedores de SA. Entre las ganancias se incluyen beneficios no monetarios para los pequeños propietarios moderadamente pobres.

- algunas reglas de acceso y restricciones estructurales obstaculizan la participación de los pobres, en tanto que otras la favorecen.

- el PSA tiene efectos mixtos en los pobres que no venden servicios, pero el pobre sin tierra que participa en actividades que degradan el ambiente es quien más podría perder con un esquema de PSA.

- la pequeña escala del PSA por lo general limita el efecto del alivio de la pobreza.

Quizás la lección más importante que debemos aprender es que si el PSA no garantiza la provisión del servicio, los compradores no continuarán apoyándolo y, entonces, el PSA no beneficiará a los pobres. Hay que cuidar de que regulaciones bienintencionadas no pongan en peligro el funcionamiento básico del PSA. El alivio de la pobreza es un importante objetivo secundario que puede alcanzarse con intervenciones a lo largo del tiempo (enfoques específicos, reducción del costo de transacción, subsidios y bonificaciones para los pobres), pero nunca debiera ser el objetivo principal. Si sobrecargamos el PSA con objetivos secundarios (alivio de la pobreza, género, indígenas, derechos humanos y otras nobles causas), el PSA se convertirá en el nuevo juguete de donantes, ONG y agencias gubernamentales. Al mismo tiempo, el alcance al sector privado será mucho más limitado y se perderán nuevas oportunidades de financiamiento. Eventualmente, el PSA se convertirá en 'vino viejo en botella nueva', subsumido en la familia genérica de altruistas proyectos de desarrollo, cuando en realidad se esperaba que fuera una alternativa válida para todos ellos. 


\section{Literatura}

Adams, W.M., R. Aveling, D. Brockington, B. Dickson, J. Elliott, J. Hutton, D. Roe, B. Vira, and W. Wolmer. 2004. Biodiversity conservation and the eradication of poverty. Science 3006:1146-1149.

Albán, M., and M. Argüello. 2004. Un análisis de los impactos sociales y económicos de los proyectos de fijación de carbono en el Ecuador. El caso de PROFAFOR - FACE. In Mercados para Servicios Ambientales, \#7. London: IIED.

Almeida, O., and C. Uhl. 1995. Developing a quantitative framework for sustainable resource use planning in the Brazilian Amazon. World Development 23:1745-1764.

Asquith, N., M. Vargas-Ríos, and J. Smith. 2002. Can forest-protection carbon projects improve rural livelihoods? Analysis of the Noel Kempff Mercado Climate Action Project, Bolivia. Mitigation and Adaptation Strategies for Global Change, 4 September 2002, 323-337.

Balmford, A., A. Bruner, P. Cooper, R. Constanza, S. Farber, R. Green, M. Jenkins, P. Jefferiss, V. Jessamy, J. Madden, K. Munro, N. Myers, S. Naeem, J. Paavola, M. Rayment, S. Rosendo, J. Roughgarden, K. Trumper, and R. Turner. 2002. Economic reasons for conserving wild nature. Science 297 (950-953).

Balmford, A., and T. Whitten. 2003. Who should pay for tropical conservation, and how could the costs be met? Oryx 37 (2):14.

Bayon, R. 2004. Making environmental markets work: Lessons from early experience with sulfur, carbon and wetlands. Washington DC: Forest Trends.

Brandon, K., K.H. Redford, and S.E. Sanderson, eds. 1998. Parks in Peril. People, politics and protected areas. Edited by T. N. Conservancy. Washington DC: Island Press.

Brundtland. 1987. Our Common Future. Report of the Brundtland Commission on Environment and Development. Oxford: Oxford University Press.

Bruner, A., R. E. Gullison, R.E. Rice, and G.A.B. da Fonseca. 2001. Effectiveness of parks in protecting tropical biodiversity. Science 291:125-128.

Costa, M.M., and M. Zeller. 2003. Peasants' production systems and the integration of incentives for watershed protection. A case study of Guatemala. Paper read at Forests, Livelihoods and Biodiversity, April 2003, at Bonn.

Deci, E. L., R. Koestner, and R. M. Ryan. 1999. A meta-analytic review of experiments examining the effects of extrinsic rewards on intrinsic motivation. Psychological Bulletin 125:627-668.

Echavarría, M., J. Vogel, M. Albán, and F. Meneses. 2004. The impacts of payments for watershed services in Ecuador. In Markets for Environmental Services. London: IIED.

Ferraro, P., and A. Kiss. 2002. Direct payments to conserve biodiversity. Science, November 29 , 2002., 1718-1719.

Ferraro, P., and R. Simpson. 2002. The costeffectiveness of conservation payments. Land Economics 78 (3):339-353.

Ferraro, P.J. 2001. Global habitat protection: limitations of development interventions and a role for conservation performance payments. Conservation Biology 15 (4):990-1000.
Grieg-Gran, M. 2000. Fiscal incentives for biodiversity conservation: The ICMS Ecológico in Brazil. In IIED Environmental Econmomics Discussion Paper \#00-01. London: International Institute for Environment and Development.

Grieg-Gran, M., I.T. Porras, and S. Wunder. 2005. How can market mechanisms for forest environmental services help the poor? Preliminary lessons from Latin America. World Development (accepted).

Gutman, P., ed. 2003. From goodwill to payments for environmental services. Washington DC: WWF, Macroeconomics for Sustainable Development Program Office.

Hanlon, J. 2004. It is possible to just give money to the poor. Development and Change 35 (2):375-383.

Hardner, J., and R. Rice. 2002. Rethinking green consumerism. Scientific American May:89-95.

Heyman, J., and D. Ariely. 2004. Effort for payment. A tale of two markets. Psychological Science 15 (11):787-793.

IPCC. 2001. Summary for policy makers. Climate change 2001. Impacts, adaptation, and vulnerability. In A report of working group II of the Intergovernmental Panel on Climate Change.: Intergovernmental Panel on Climate Change.

James, A., K. Gaston, and A. Balmford. 2001. Can we afford to conserve biodiversity? BioScience, 43-52.

Kaimowitz, D. 2004. Forest and water: a policy perspective. Journal for Forest Research (9):289291.

Karsenty, A. 2004. Des rentes contre le développement? Les nouveaux instruments d'acquisition mondiale de la biodiversité et l'utilisation des terres dans les pays tropicaux. Mondes en développement $127(3): 1-9$.

Karsenty, A., and R. Nasi. 2004. Un commentaire sur l'article de E.Niesten et R.Rice. Les "concessions de conservation" sonnent-elles le glas de l'aménagement forestier durable? Revue Tiers Monde XLV (177):153-162.

Kerr, J. 2002. Watershed development, environmental services, and poverty alleviation in India. World Development 30 (8):1387-1400.

Landell-Mills, N., and I.T. Porras. 2002. Silver bullet or fool's gold? A global review of markets for for forest environmental services and their impact on the poor, Instruments for Sustainable Priovate Sector Forestry. London: IIED.

Margulis, S. 2003. "Causas do desmatamento de Amazônia brasileira." 100. World Bank: Brasília.

May, P.H., F. Veiga Neto, V. Denardin, and W. Loureiro. 2002. Using fiscal instruments to encourage conservation: municipal responses to the 'ecological' value-added tax in Paraná and Minas Gerais, Brazil. In Selling forest environmental services. Market-based mechanisms for conservation and development., edited by $\mathrm{S}$. Pagiola, J. Bishop and N. Landell-Mills. London \& Sterling: Earthscan.

Milne, M. 2000. Forest carbon, livelihoods and biodiversity. A report to the European Commission. Bogor: CIFOR.

Miranda, M., I. Porras, and M. Moreno. 2003. The social impacts of payments for environmental services in Costa Rica. In Markets for environmental services \#1. London: IIED. 
Miranda, M., I.T. Porras, and M.L. Moreno. 2004. The social impacts of carbon markets in Costa Rica. A case study of the Huetar Norte region. In MES. London: IIED.

Mohr, E. 1990. Burn the forest!: a bargaining theoretic analysis of a seemingly perverse proposal to protect the rainforest: Kiel Institute of World Economics.

Muñoz, R. 2004. Efectos del programa de servicios ambientales en las condiciones de vida de los campesinos de la Península de Osa, (thesis), Evaluación de Programas y Proyectos de Desarrollo, Universidad de Costa Rica, San José.

Niesten, E., S. Ratay, and R. Rice. 2004. Achieving biodiversity conservation using conservation concessions to complement agroforestry. In Agroforestry and biodiversity conservation in tropical landscapes, edited by G. Schroth, G. A. B. da Fonseca, C. A. Harvey, C. Gascon, H. L. Vasconcelos and A.-M. N. Izac. Wasington, Covelo \& London: Island Press.

Niesten, E., and R. Rice. 2004. Sustainable forest management and conservation incentice agreements. International Forestry Review 6:56-60.

Pagiola, S., P. Agostini, J. Gobbi, C. de Haan, M. Ibrahim, E. Murgueitio, E. Ramírez, M. Rosales, and P.R. Ruíz. 2004. Paying for biodiversity conservation services in agricultural landscapes. In Environment Department Paper \#96. Washinton DC: World Bank.

Pagiola, S., A. Arcenas, and G. Platais. 2005. Can payments for environmental services help reduce poverty? An exploration of the issues and the evidence to date. World Development 33 (2):237-253.

Pagiola, S., J. Bishop, and N. Landell-Mills, eds. 2002. Selling forest environmental services. Market-based mechanisms for conservation and development. London \& Sterling: Earthscan.

Pagiola, S., and I.-M. Ruthenberg. 2002. Selling biodiversity in a coffee cup: shade-grown coffee and conservation in Mesoamerica. In Selling forest environmental services. Market-based mechanisms for conservation and development. edited by S. Pagiola, J. Bishop and N. LandellMills. London \& Sterling: Earthscan.

Pearce, D., F. Putz, and J. Vanclay. 2003. Sustainable forestry in the tropics: panacea or folly? Forest Ecology and Management 172 (2-3):229-247.

Poore, D.P. 2003. Changing landscapes. The development of the International Tropical Timber Organization and its influence on tropical forest management. London \& Sterling: Earthscan.

Rice, D., R.E.Gullison and J.W.Reid. 1997. Can sustainable management save tropical forests? New York: Scientific American.

Robertson, N., and S. Wunder. 2005. Fresh tracks in the forest: Assessing incipient payments for environmental services initiatives in Bolivia (draft). In CIFOR. Bogor.

Rojas, M., and B. Aylward. 2003. What are we learning from experiences with markets for environmental services in Costa Rica? A review and critique of the literature, November, 102.

Romero, C., and G.I. Andrade. 2004. International conservation organizations and the fate of local tropical forest conservation initiatives. Conservation Biology 18 (2):578-580.
Rosa, H., S. Kandel, and L. Dimas. 2003. Compensation for environmental services and rural communities. San Salvador: PRISMA.

Salafsky, N., and E. Wollenberg. 2000. Linking livelihoods and conservation: A conceptual framework and scale for assessing the integration of human needs and biodiversity. World Development 28 (8):1421-1438.

Sayer, J.A. 1995. Science and international nature conservation. Bogor, Indonesia: Center for International Forestry Research (CIFOR).

Scherr, S., A. Khare, and A. White. 2004. For services rendered. Current status and future potential of markets for ecosystem services of tropical forests: an overview. In Technical Series \#21. Yokohama: International Tropical Timber Organization (ITTO).

Scherr, S., A. White, and A. Khare. 2004. Tropical forests provide the planet with many valuable services. Are beneficiaries prepared to pay for them? ITTO Tropical Forest Update 14 (2):11-14.

Shilling, J., and J. Osha. 2003. Paying for environmental stewardship. Washington DC: WWF Macroeconomics for Sustainable Development Program Office.

Simpson, R., and R.A. Sedjo. 1996. Paying for the conservation of endangered ecosystems: a comparison of direct and indirect approaches. Environment and Development Economics 1:241. 257.

Smith, J., and S. Scherr. 2002. Forest carbon and local livelihoods: assessment of opportunities and policy recommendations. In CIFOR Occasional Paper. Bogor, Indonesia: CIFOR.

Sokolow, A.D., and A. Zurbrugg. 2003. A national view of agricultural easement programs. Davis (CA): Center for Agriculture in the Environment, American Farmland Trust.

van Noordwijk, M., F. Chandler, and T.P. Tomich. 2004. An introduction to the conceptual basis of RUPES. In Rewarding Upland Poor for Envrionmental Services. Bogor: ICRAF - World Agroforestry Center.

Vogel, J. 2002. Markets or metaphors? A sustainable livelihoods approach to the management of environmental services: two cases from Ecuador. London \& Quito: IIED \& Ecodecisión.

Wunder, S. 2001. Poverty alleviation and tropical forests - what scope for synergies? World Development 29 (11):1817-1833.

Wunder, S., B. Campbell, R. Iwan, J.A. Sayer, and L. Wollenberg. 2004. When donors get cold feet: The community conservation concession in Setulang (Kalimantan, Indonesia) that never happened, chapter for submitted for Bishop, Pagiola \& Wunder (eds): Buying biodiversity (Earthscan).

Wunder, S., Bui Dung The, and E. Ibarra. 2005. Payment is good, control is better: why payments for environmental services so far have remained incipient in Vietnam (draft). In CIFOR. Bogor.

Wunder, S., and M.T. Vargas. Beyond "markets" - why terminology matters 2005, March 2005, Available from http://ecosystemmarketplace. net/pages/article.opinion.php?component $i d=1252 \&$ component_version_id=2354\&language _ $i d=12$ 


\section{CIFOR Occasional Paper Series}

1. Forestry Research within the Consultative Group on International Agricultural Research

Jeffrey A. Sayer

2. Social and Economical Aspects of Miombo Woodland Management in Southern Africa: Options and Opportunities for Research Peter A. Dewees

3. Environment, development and poverty: A Report of the International Workshop on India's Forest Management and Ecological Revival Uma Lele, Kinsuk Mitra and O.N. Kaul

4. Science and International Nature Conservation Jeffrey A.Sayer

5. Report on the Workshop on Barriers to the Application of Forestry Research Results

C.T.S. Nair, Thomas Enters and B. Payne

6. Production and Standards for Chemical Non-Wood Forest Products in China

Shen Zhaobang

7. - Cattle, Broadleaf Forests and the Agricultural Modernization Law of Honduras: The Case of Olancho

- (Spanish edition) Ganadería, bosques latifoliaods y Ley de Modernizatción en Honduras: El caso de Olancho William D. Sunderlin and Juan A.Rodriguez

8. High quality printing stock - has research made a difference? Francis S.P. $\mathrm{Ng}$

9. - Rates Causes of Deforestation in Indonesia: Towards a Resolution of the Ambiguities

- (Indonesian edition) Laju dan Penyebab Deforestasi di Indonesia: Penelaahan Kerancuan dan Penyelesaiannya William D. Sunderlin and Ida Aju Pradnja Resosudarmo

10. Report on Discussion Forum on Irformation Services in the AsiaPacific and AGRIS/CARIS in the 21st Century and Asia-Pacific Regional Consultation

Michael O. Ibach and Yvonne Byron

11. Capacity for Forestry Research in the Southern African Development Community

Godwin S. Kowero and Michael J. Spilsbury

12. Technologies for sustainable forest management: Challenges for the $21 \mathrm{st}$ century

Jeffrey A. Sayer, Jerome K. Vanclay and R. Neil Byron

13. Bosques secundarios como recurso para el desarrollo rural y la conservación ambiental en los trópicos de América Latina Joyotee Smith, César Sabogal, Wil de Jong and David Kaimowitz

14. Cameroon's Logging Industry: Structure, Economic Importance and Effects of Devaluation Richard Eba'a Atyi

15. - Reduced-Impact Logging Guidelines for Lowland and Hill Dipterocarp Forests in Indonesia

- (Indonesian edition) Pedoman Pembalakan Berdampak Rendah untuk Hutan Dipterocarpa Lahan Rendah dan Bukit di Indonesia Plinio Sist, Dennis P. Dykstra and Robert Fimbel

16. Site Management and Productivity in Tropical Forest Plantations A. Tiarks, E.K.S. Nambiar and Christian Cossalter

17. Rational Exploitations: Economic Criteria and Indicators for Sustainable Management of Tropical Forests Jack Ruitenbeek and Cynthia Cartier

18. Tree Planting in Indonesia: Trends, Impacts and Directions Lesley Potter and Justin Lee

19. Le Marche des Produits Forestiers Non Ligneux de l'Afrique Centrale en France et en Belgique: Produits, Acteurs, Circuits de Distribution et Debouches Actuels

Honoré Tabuna

20. Self-Governance and Forest Resources Elinor Ostrom

21. Promoting Forest Conservation through Ecotourism Income? A case study from the Ecuadorian Amazon region Sven Wunder

22. Una de Gato: Fate and Future of a Peruvian Forest Resource Wil de Jong, Mary Melnyk, Luis Alfaro Lozano, Marina Rosales and Myriam García

23. Les Approches Participatives dans la Gestion des Ecosystemes Forestiers d'Afrique Centrale: Revue des Initiatives Existantes Jean-Claude Nguinguiri

24. Capacity for Forestry Research in Selected Countries of West and Central Africa

Michael J. Spilsbury, Godwin S. Kowero and F. Tchala-Abina
25. L'Ímpact de la Crise Economique sur les Populations, les Migration et le Couvert Forestier du Sud-Cameroun

Jacques Pokam Wadja Kemajou and William D.Sunderlin

26. - The Impact of Sectoral Development on Natural Forest Conservation and Degradation: The Case of Timber and Tree Crop Plantations in Indonesia

- (Indonesian edition) Dampak Pembangunan Sektoral terhadap Konversi dan Degradasi Hutan Alam: Kasus Pembangunan HTI dan Perkebunan di Indonesia Hariadi Kartodihardjo and Agus Supriono

27. L'Impact de la Crise Économique sur les Systèmes Agricoles et le Changement du Couvert Forestier dans la Zone Forestière Humide du Cameroun Henriette Bikié, Ousseynou Ndoye and William D.Sunderlin

28. - The Effect of Indonesia's Economic Crisis on Small Farmers and Natural Forest Coverin the Outer Islands

- (Indonesian Edition) Dampak Krisis Ekonomi Indonesia terhadap Petani Kecil dan Tutupan Hutan Alam di Luar Jawa

William D. Sunderlin, Ida Aju Pradnja Resosudarmo, Edy Rianto, Arild Angelsen

29. The Hesitant Boom: Indonesia's Oil Palm Sub-Sector in an Era of Economic Crisis and Political Change Anne Casson

30. The Underlying Causes of Forest Decline Arnoldo Contreras-Hermosilla

31. 'Wild logging': The rise and fall of logging networks and biodiversity conservation projects on Sumatra's rainforest frontier John F. McCarthy

32. Situating Zimbabwe's Natural Resource Governance Systems in History Alois Mandondo

33. Forestry, Poverty and Aid J.E. Michael Arnold

34. The Invisible Wand: Adaptive Co-management as an Emergent Strategy in Complex Bio-economic systems. Jack Ruitenbeek and Cynthia Cartier

35. Modelling Methods for Policy Analysis in Miombo Woodlands

A. A Goal Programming Model for Planning Management of Miombo Woodlands

I. Nhantumbo and Godwin S. Kowero

B. A System Dynamics Model for Management of Miombo Woodlands Ussif Rashid Sumaila, Arild Angelsen and Godwin S. Kowero

36. How to Know More about Forests? Supply and Use of Information for Forest Policy K. Janz and R. Persson

37. Forest Carbon and Local Livelihoods: Assessment of Opportunities and Policy Recommendations Joyotee Smith and Sara J. Scherr

38. - Fires in Indonesia: Causes, Costs and Policy Implication - (Indonesian edition) Kebakaran Hutan di Indonesia: Penyebab, Biaya dan Implikasi Kebijakan

Luca Tacconi

39. Fuelwood Revisited: What Has Changed in the Last Decade? Michael Arnold, Gunnar Köhlin, Reidar Persson and Gillian Shepherd

40. Exploring the Forest-Poverty Link: Key concepts, issues and research implications Arild Angelsen and Sven Wunder

41. $\quad$ Bridging the Gap: Communities, Forests and International Networks - (French Edition) Communautés, forêts et réseauxinternationaux des liaisons à renforcer

- (Spanish Edition) Cerrando la Brecha: Comunidades,Bosques y Redes Internacionales

Marcus Colchester, Tejaswini Apte, Michel Laforge, Alois Mandondo and Neema Pathak

42. Payments for environmental services: Some nuts and bolts Sven Wunder

43. Recent Experience in Collaborative Forest Management: A Review Paper Jane Carter with Jane Gronow

44. - Fighting forest crime and promoting prudent banking for sustainable forest management: The anti money laundering approach

- (Indonesian edition) Memerangi Kejahatan Kehutanan dan Mendorong Prinsip Kehati-hatian Perbankan untuk Mewujudkan Pengelolaan Hutan yang Berkelanjutan: Pendekatan Anti Pencucian Uang Bambang Setiono and Yunus Husein

45. Forests and Human Health: Assessing the Evidence Carol J. Pierce Colfer, Douglas Sheil and Misa Kish 
Las Publicaciones Especiales del CIFOR ofrecen resultados de investigaciones particularmente significativas para la forestería tropical. El contenido de cada trabajo es escudriñado por revisores internos y externos y publicado simultáneamente en Internet, en formato descargable (www.cifor.cgiar.org/ publications/papers).

Si desea solicitar copias, favor contactar a cifor@cgiar.org

El Centro Internacional de Investigación Forestal (CIFOR) fue creado en 1993, como parte del Grupo Consultivo Internacional en Investigación Agrícola (CGIAR) y en respuesta a preocupaciones mundiales por las consecuencias sociales, ambientales y económicas provocadas por la pérdida y degradación de los bosques. La investigación del CIFOR genera conocimientos y métodos necesarios para mejorar el bienestar de quienes dependen del bosque y para ayudar a los países tropicales a manejar sus bosques apropiadamente de manera que rindan beneficios sostenibles. Las investigaciones tienen lugar en más de dos docenas de países, en colaboración con numerosas organizaciones. Desde su fundación, CIFOR también ha influido de manera determinante en la formulación de políticas forestales a nivel nacional y mundial.

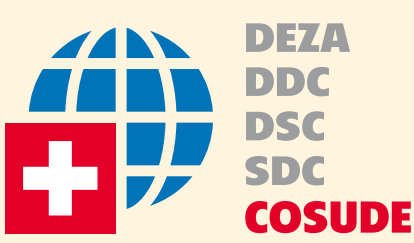

CIFOR is uno de los 15 centros de Futura Cosecha del Grupo Consultativo Internacional en Investigación Agrícola (CGIAR). 